University of Redlands

\title{
A Geographic Information System for Salt Marsh Mosquito Control in Naval Base Ventura County Point Mugu
}

A Major Individual Project submitted in partial satisfaction of the requirements for the degree of Master of Science in Geographic Information Systems

by

Charles Adi Vuchiteh

Fang Ren, Ph.D., Committee Chair

Ruijin Ma, Ph.D.

$2 / 3 / 2017$ 
A Geographic Information System for Salt Marsh Mosquito Control in Naval Base Ventura County Point Mugu

Copyright (C) 2017

by

Charles Adi Vuchiteh 
The report of Charles Adi Vuchiteh is approved.

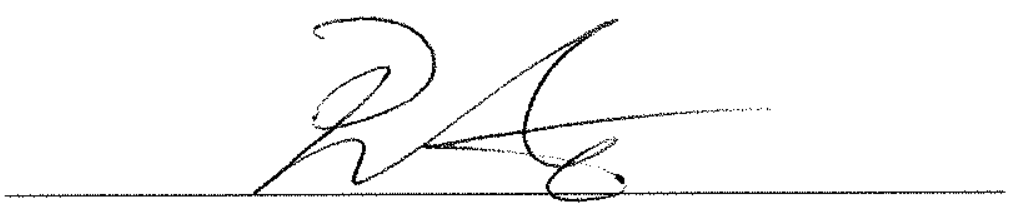

Ruijin Ma, Ph.D.

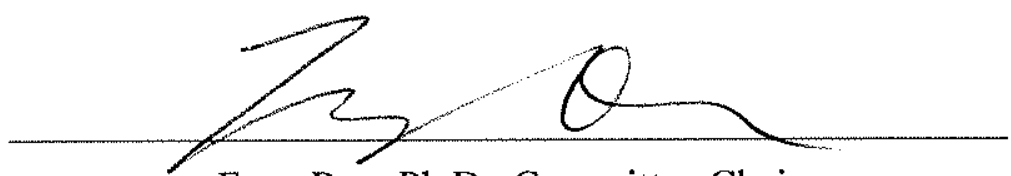

Fang Ren, Ph.D., Committee Chair

February 2017 



\section{Acknowledgements}

I would like to thank God Almighty for abundant grace and blessings throughout my stay in Redlands. My appreciation to my advisor, Prof. Fang Ren for her contribution to the realization of this work. Despite her tight schedule, she was greatly committed in every piece of this work with constructive layout and execution of this research.

My immense thanks to the Program Director, Coordinator and staff of the MS GIS program of the University of Redlands for their moral and material support throughout my studies. Prof. Flewelling, Prof. Ma, and Prof. Kumler your contribution and critiques made this work a success. A big thank you to my friends of Cohort 29 for your support and encouragement. Your collaboration and cooperation throughout our program was fantastic. I would also like to thank my client, Valerie Vartanian and Sara Wetherbee of NBVC Point Mugu for your time and support in making it possible to realize this project added to your busy schedule.

My deep appreciation goes to the Nsoyuni's Family, Tunyi's Family, Wongeh's Family, my aunts and uncles whom your support and encouragement have been a driving force in my career. My sincere thanks to John Y. and family, Dr. Chi, Dr. Enoh, James O, Ciiru, Joseph M., Victoria M., Qian and others, you gave me the joy of a family throughout my studies in Redlands. Thank you James and Ciiru for your support and guidance in this work. I love you all.

To my entire family and siblings, Pa and Ma Adi, Blaise, Mary, Dick, Elizabeth and Queen, my niece and nephew, cousins, I say thank you for your material, moral and spiritual support throughout my studies. You are always there with me. Heartfelt thanks to Brenda for your love, care and support throughout my study. You are so dear to me. 



\begin{abstract}
A Geographic Information System for Salt Marsh Mosquito Control in Naval Base Ventura County Point Mugu

by

Charles Adi Vuchiteh

The project was about developing a GIS solution for salt marsh mosquito control in Naval Base Ventura County Point Mugu (NBVC), a United States Naval Station. The Point Mugu Naval base was faced with nuisance of black salt marsh mosquitos every mosquito season which affects a population of aproximately1546 civilian, military personnel's and their dependents that live on sites. The Naval Base needed to identify potential areas for salt marsh mosquito breeding and thus develop a method to Control and monitor the pests while minimizing harm to people and the environment. To solve this problem, a GIS solution was proposed that entailed combination of the modified bathtub approach and ArcGIS spatial analyst functions for prediction of potential salt marsh mosquito breeding sites, developing a spatial database, and producing series of maps. The results included a predictive potential site model of possible mosquito breeding areas, a geodatabase to record and track mosquito control data, and maps to guide field work. Developing a GIS solution for salt marsh mosquito control provided a decision-making support to help the NBVC Point Mugu adapt and adopt a new control management approach by prioritizing control effort to reduce mosquito populations.
\end{abstract}





\section{Table of Contents}

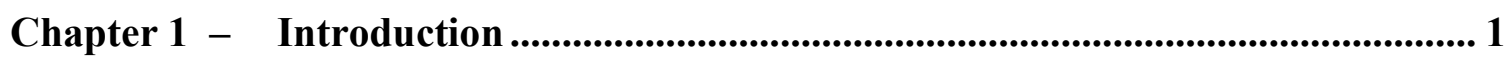

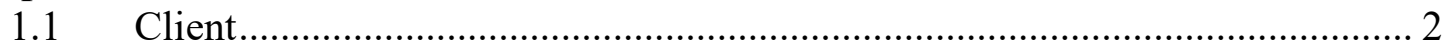

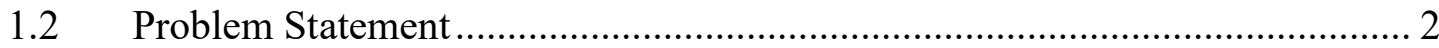

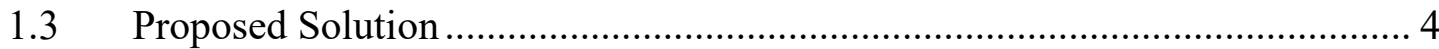

1.3.1 Goals and Objectives ............................................................................. 4

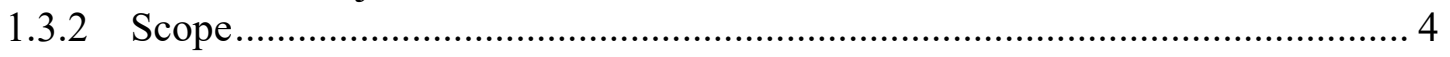

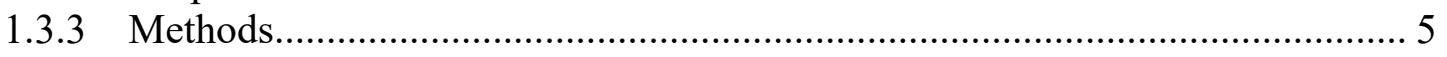

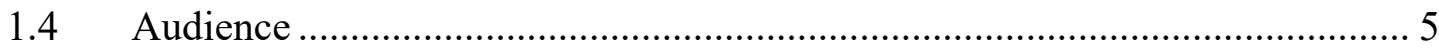

1.5 Overview of the Rest of this Report ………………................................. 5

Chapter 2 - Background and Literature Review ............................................................. 7

$2.1 \quad$ Mosquito Life Cycle, Habitats, and Impact .................................................... 7

2.1.1 Mosquito Life Cycle ……………………………...................................... 7

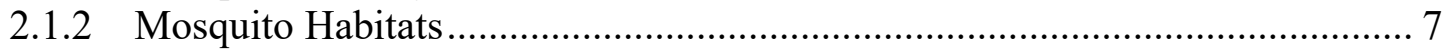

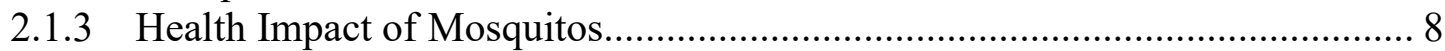

2.2 Mosquito Control and Management .......................................................... 8

2.2.1 Mosquito Control Programs in the U.S. .......................................................... 8

2.2.2 Mosquito Control Using Geographic Information Systems (GIS) ................... 9

2.2.3 Modeling Inundation for Mosquito Habitat ................................................... 9

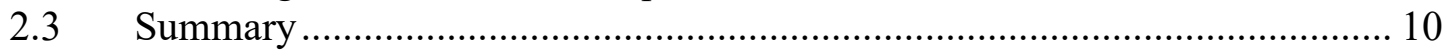

Chapter 3 - Systems Analysis and Design............................................................... 13

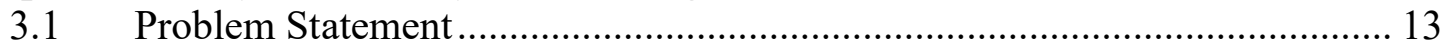

3.2 Requirements Analysis .......................................................................... 13

3.2.1 Functional Requirements ........................................................................ 13

3.2.2 Non-Functional Requirements .................................................................. 14

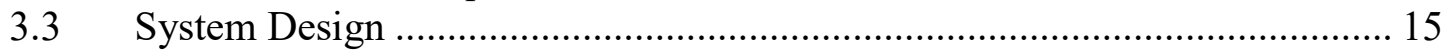

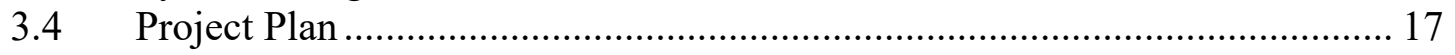

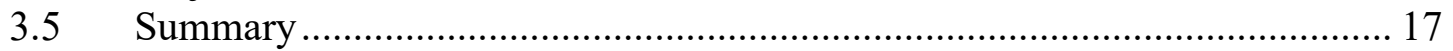

Chapter 4 - Database Design............................................................................................. 19

4.1 Conceptual Data Model ........................................................................ 19

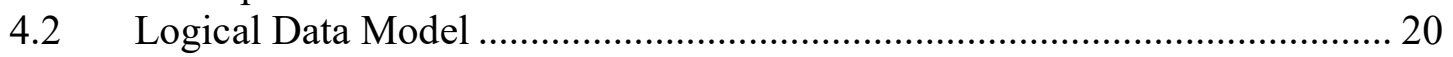

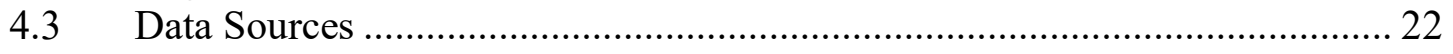

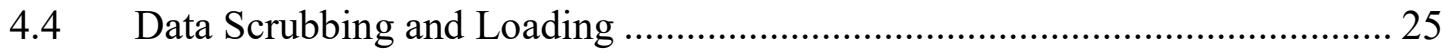

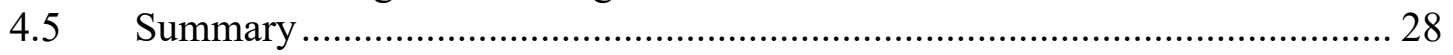

Chapter 5 - Implementation.............................................................................................. 29

$5.1 \quad$ Predicting Potential Breeding Sites ............................................................ 29



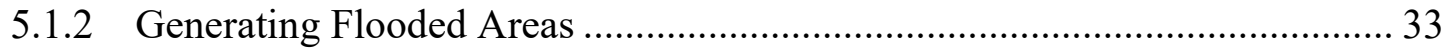

5.1.3 Generating Drainage of Point Mugu Lagoon............................................... 35

5.1.4 Generating Potential Sites........................................................................... 36

5.1.5 Building an Interface for Generating Potential Breeding Sites ....................... 36

5.2 Proximity analysis of prioritized sites............................................................. 37




Chapter 6 - Results and Analysis................................................................................ 41



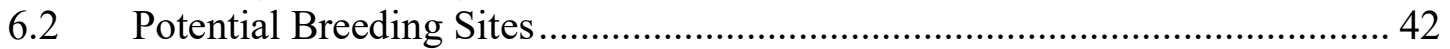

6.3 Validating Predicted Breeding Sites ..................................................... 45

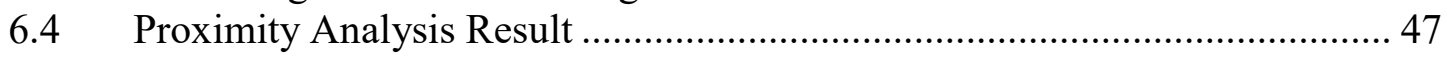

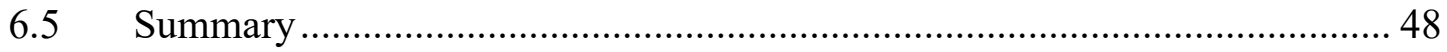

Chapter 7 - Conclusions and Future Work......................................................... 51

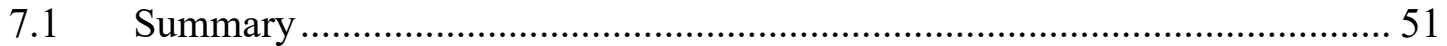



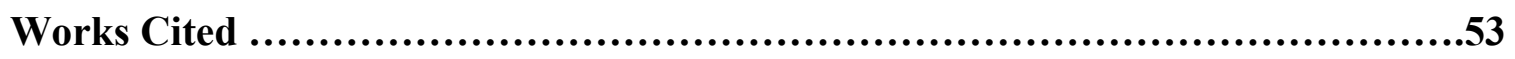

Appendix A. Predicting Potential Site Model Diagram ............................................ 55

Appendix B. Overview of Vegetation cover and Potential Sites............................. 56 


\section{Table of Figures}

Figure 1-1: Location of NBVC Point Mugu ..............................................................

Figure 1-2: Photo of NBVC Point Mugu marsh taken in 2016 ................................... 3

Figure 1-3: Photo of a typical salt marsh NBVC Point Mugu taken in 2016 ...............3



Figure 4-1: Conceptual Data Model .....................................................................2

Figure 4-2: Logical data model showing the physical geodatabase design ................21

Figure 4-3: Map of Infrastructure and hydrology from client's dataset .....................2.



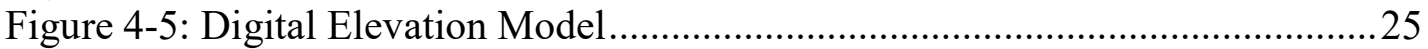

Figure 4-6: Data migration, creation and organization of the spatial database .........26

Figure 4-7: Process of creating the mosquito control dataset.....................................26

Figure 4-8: Process of migrating datasets necessary for analysis and basemap ........27

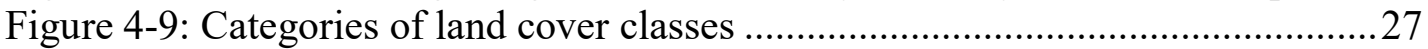

Figure 5-1: Workflow of the predictive potential sites model....................................29

Figure 5-2: Reference point for tidal height and DEM............................................ 31

Figure 5-3: Workflow for generating tidal surface .....................................................31

Figure 5-4: Grid point text file before and after transformation...................................32

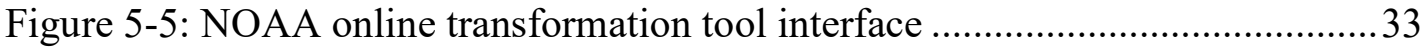

Figure 5-6: Workflow for generating flooded areas .................................................... 33

Figure 5-7: Conditional Expression in Raster Calculator .............................................34

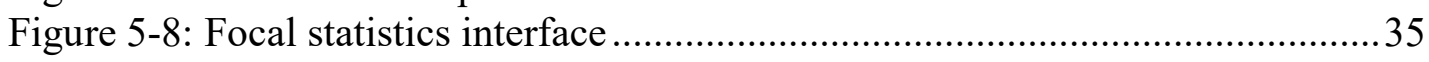

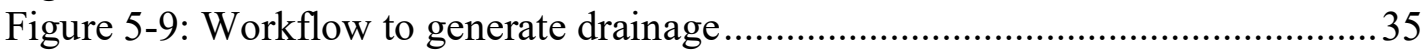

Figure 5-10: Workflow generating potential sites .....................................................



Figure 5-12: Proximity analysis of prioritized sites.................................................. 38

Figure 5-13: Proximity for prioritized sites model interface ……………………........ 38

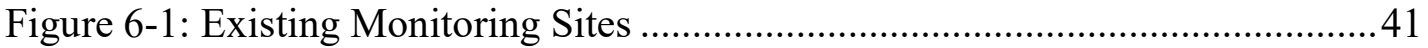



Figure 6-3: Flooded areas after noise was removed ................................................4 43

Figure 6-4: Point Mugu Lagoon drainage................................................................ 44

Figure 6-5: Potential salt marsh mosquito breeding sites (predictive model output) 45

Figure 6-6: Overview of potential sites and existing monitoring sites ........................46 Figure 6-7: Mosquito monitoring sites showing existing sites "Monitoring" and new



Figure 6-8: Prioritized sites from proximity analysis ................................................4 48 



\section{List of Tables}

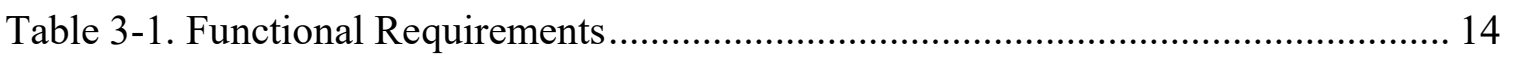

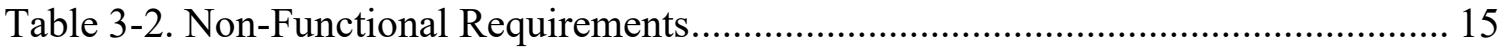





\section{List of Acronyms and Definitions}

$\begin{array}{ll}\text { CDC } & \text { Centers for Disease Control and Prevention } \\ \text { CSDGM } & \text { Content Standard for Digital Geospatial Metadata } \\ \text { DEM } & \text { Digital Elevation Model } \\ \text { EPA } & \text { Environmental Protection Agency } \\ \text { FEMA } & \text { Federal Emergency Management Agency } \\ \text { FGDC } & \text { Federal Geographic Data Committee } \\ \text { MHHW } & \text { Mean Higher High Water } \\ \text { MSL } & \text { Mean Sea Level } \\ \text { NBVC } & \text { Naval Base Ventura County } \\ \text { NOAA } & \text { National Oceanic and Atmospheric Administration } \\ \text { SLR } & \text { Sea Level Rise } \\ \text { SPC } & \text { State Plane Coordinate } \\ \text { WGS } & \text { World Geodetic System }\end{array}$





\section{Chapter 1 - Introduction}

United States Naval Station Naval Base Ventura County (NBVC) is located in Ventura County on the central coast of California between Santa Barbara and Los Angeles and includes three main facilities: San Nicolas Island, Port Hueneme, and Point Mugu. Figure 1-1 shows the location of NBVC Point Mugu. NBVC Point Mugu is located about 50 miles northwest of Los Angeles, California. It shares a border with the cities of Oxnard, Camarillo, Newbury Park, Thousand Oaks, Port Hueneme, and Ventura. To the north and northwest of NBVC Point Mugu are Point Mugu Game Reserve and Ventura County Game Reserve, while south and west are the Pacific Ocean and Ormond Beach respectively. Of NBVC Point Mugu's 1817 hectares (ha) surface area, approximately 890 ha are jurisdictional delineated wetlands, representing the largest remaining coastal salt marsh estuary in Southern California (NBVC, 2012a).

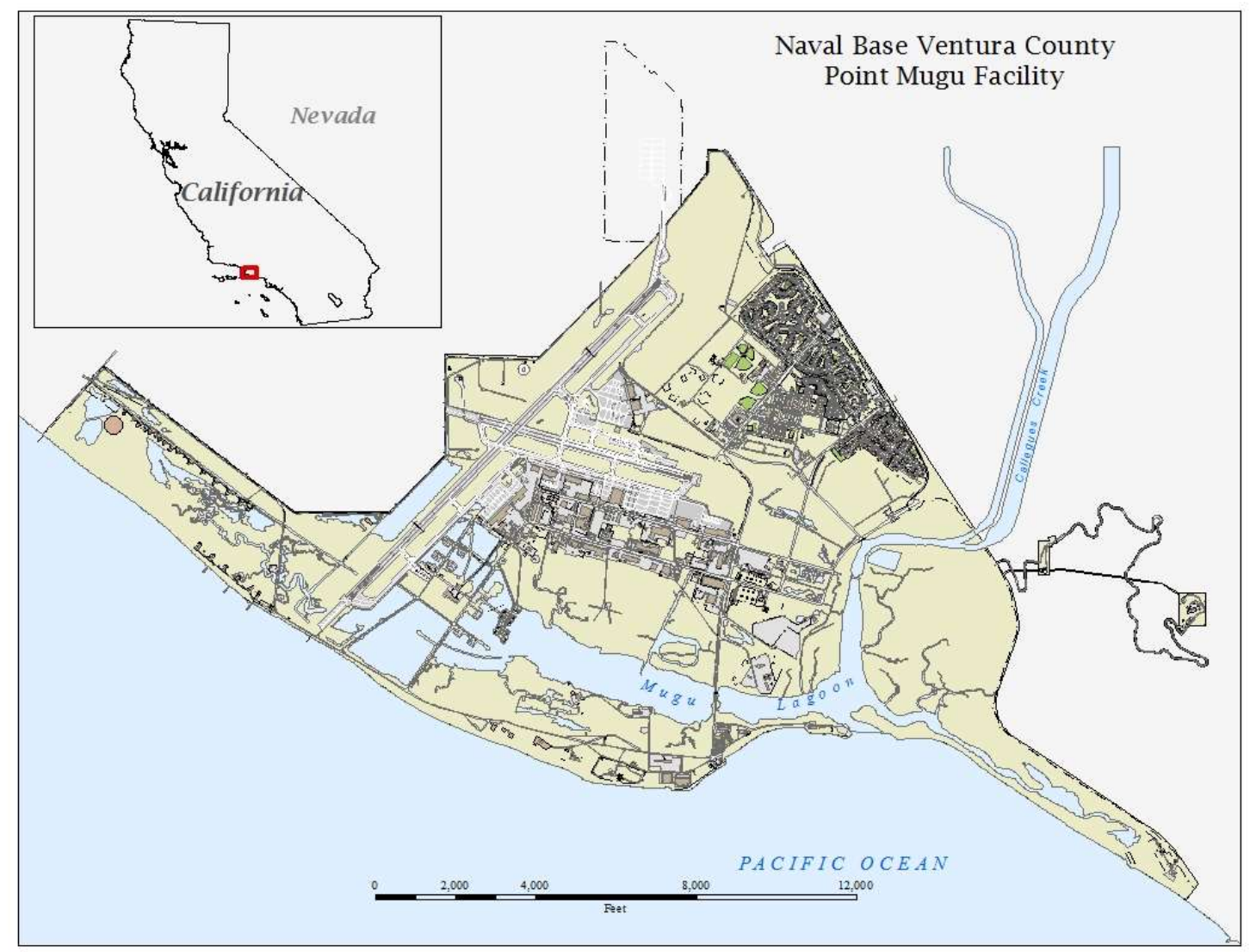

\section{Figure 1-1: Location of NBVC Point Mugu}

NBVC Point Mugu has numerous mosquito breeding areas on and around the installation. The most common and problematic species is Aedes taeniorhnchus also known as the black salt marsh mosquito. They breed in the upper marshes of Mugu Lagoon. They are at their worst shortly after extreme high tides during the summer and early fall. This species is vicious day or night biters that fly long distances in search of a 
host meal. Point Mugu covers the largest habitat of this species in this part of Southern California. Mosquitoes as far as Simi Valley and Malibu have been traced to breeding on Point Mugu. Point Mugu spends much of its pest control resources on mosquito surveillance and control.

This project focused on a geographic information system (GIS) approach to predicting potential salt marsh mosquito breeding sites and the predicted areas would be integrated into the mosquito control plan of NBVC Point Mugu for implementation. Tasks involved in this project included building a file geodatabase, developing a model to determine potential sites, performing analysis to determine treated areas from untreated areas, and overlaying of the breeding areas.

\subsection{Client}

The client for this project was the Environmental Division of the Public Works Department at Naval Base Ventura County Point Mugu and the contact persons were Valerie Vartanian, the Natural Resources Manager at NBVC, and Sara Wetherbee, a GIS analyst. The mission of NBVC Point Mugu is to support the fleet, fighter and family by providing effective and efficient readiness for shore activities such as storms (NBVC, 2012b). The clients provided reference information about NBVC Point Mugu regarding the specific purpose of the project, including the dataset needed for the project.

NBVC Point Mugu is one of the facilities that participate in the joint effort to control mosquitos. The key concern in this study was to incorporate GIS into the mosquito control plan using a model to predict potential breeding sites (hotspots) to create a safe and healthy environment for outdoor activities by reducing the salt marsh mosquitos.

\subsection{Problem Statement}

NBVC Point Mugu contains ecological diversity, providing rich tidal wetlands for species groups. It is also the largest coastal salt marsh estuary in Southern California, which becomes favored breeding sites for black salt marsh mosquitos. Since the mosquitos imposed great danger for outdoor activities, the Environmental Division of the Public Work Department of NBVC Point Mugu was searching for methods and solutions to reduce this species without posing significant threat to the public and environment. Figure 1-2 shows the marsh while Figure 1-3 is a typical salt marsh photo - salt marsh mosquito breeding areas. 


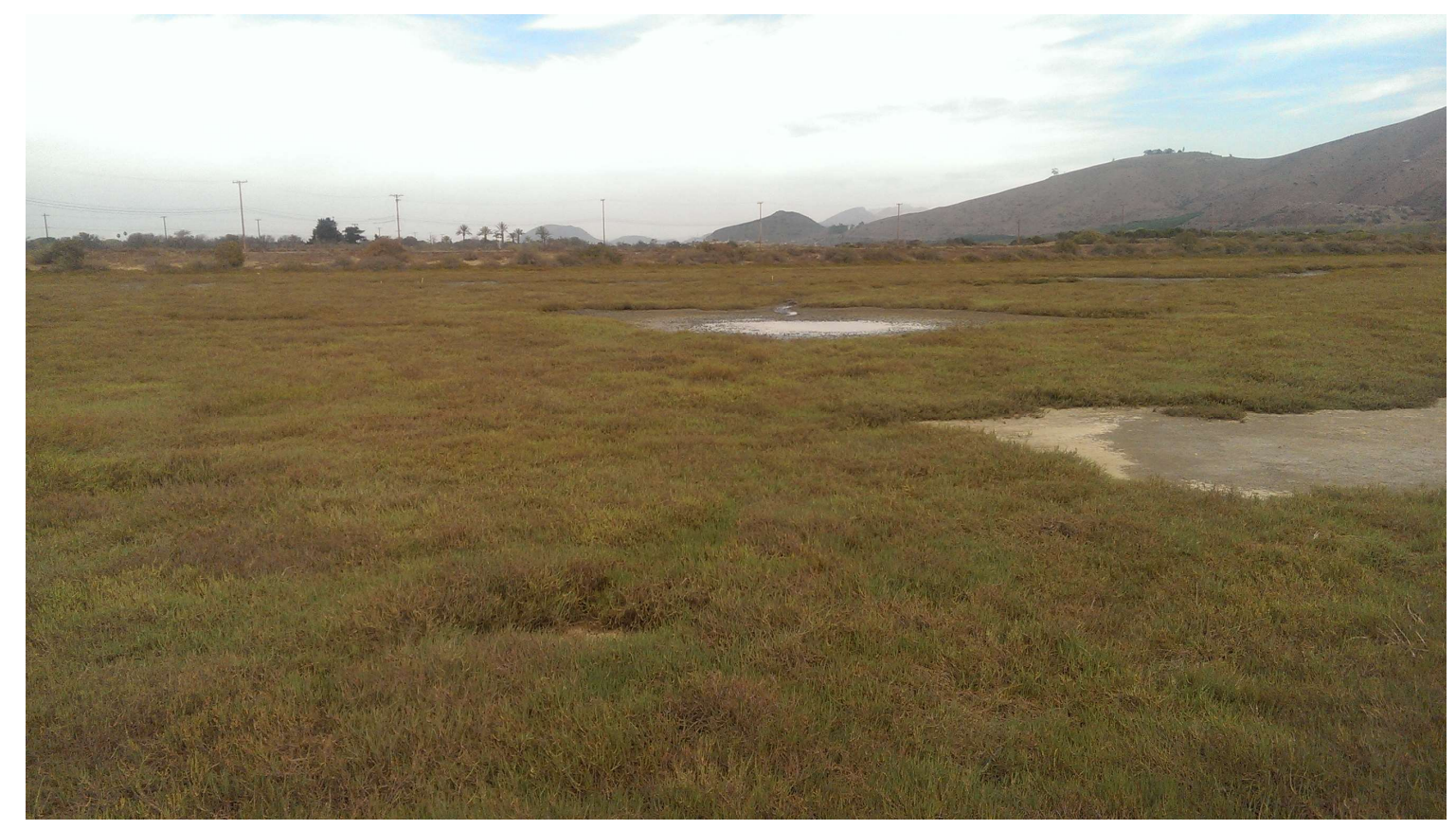

Figure 1-2: Photo of NBVC Point Mugu marsh taken in 2016



Figure 1-3: Photo of a typical salt marsh NBVC Point Mugu taken in 2016

In particular, the NBVC Point Mugu Mosquito Control Program needed to identify breeding grounds for salt marsh mosquitos. Although the client had collected samples of breeding grounds in the field, this method was expensive and inefficient. They needed a better solution for locating new breeding sites and determining how effective the 
application of treatments is. This information will be used to develop an effective control strategy plan for controlling the mosquito population within the study area.

\subsection{Proposed Solution}

Spatially enabling the mosquito control and monitoring operations was the key solution offered to solve the issue at hand at the time. This helped the client to collect and store information in a meaningful manner, which in turn powered the analytical work to help determine the potential breeding areas as well as the tracking and monitoring of the mosquitos. To accomplish this, a file geodatabase was developed in ArcGIS to store all the information collected from the surveillance activities. The database incorporated feature classes and tables for routine use and constant updates after this project is completed. The overall process was to build a file geodatabase for spatial analysis such as querying, selecting, and displaying mapped breeding and treatment locations. A model was then built to help predict the potential breeding areas based on the trends and patterns gathered from the data collected during the surveillance activities.

\subsubsection{Goals and Objectives}

The goal of the project was to incorporate GIS in the NBVC Point Mugu control and monitoring programs to help better manage and control the impact of the salt marsh mosquitos. The key concern was to improve safety for outdoor activities by reducing salt marsh mosquitos.

There were three primary objectives to meet the client's needs. The first was to utilize their data to create a standardized database for the client to store and organize their data. The database should be easily updated in the future. The second objective was to identify potential salt marsh mosquito habitats based on factors affecting the lagoon, with which the client can target the areas to apply treatments. The third objective was to categorize the breeding areas as treated and untreated areas. In doing so, the client can better track their work progress and schedules.

\subsubsection{Scope}

The scope of the project was to develop a file geodatabase using ArcGIS as the development environment to identify salt marsh mosquito breeding grounds, treated and untreated. The file geodatabase should support the mosquito control program and store the information generated by routine control activities. The file geodatabase provides upto-date outputs to be used by a field collector. The second main deliverable was a model designed to predict potential salt marsh mosquito breeding sites. The model was the major task for the project that would help the client predict and identify the potential breeding areas for the mosquitos. The model was a solution designed and implemented as a desktop tool created using the ArcGIS Desktop 10.3.1 and ModelBuilder. The model, portable document format (PDF) maps of potential sites, treatment sites, and a report were also part of the final deliverables. 


\subsubsection{Methods}

Since salt marsh mosquitos' breeding relies on water, it was necessary to identity the areas that retain water after tidal activity. The project was designed to generate potential mosquito breeding sites as a result of predicted sea level rise and tidal surface over the digital elevation model (DEM) of Point Mugu. A tidal surface terrain was created using data derived from Vertical Datum (VDatum) transformation - an online software tool developed by NOAA for water surface transformation. This surface was then compared with the digital elevation model (DEM) to retrieve low areas that are highly vulnerable to inundation. To better visualize the result, a terrain model was created and the $3 \mathrm{D}$ water surface was draped onto the terrain surface.

The existing salt marsh mosquito larvae habitats were then compared to the areas that are subject to inundation to determine how well the field samples matched the estimated inundated areas. With the validation of the predicted breeding areas, these sites were then earmarked and digitized into the existing breeding sites.

\subsection{Audience}

The intended audience of the project was the Environmental Division of the Public Work Department at NBVC Point Mugu. The GIS unit, in conjunction with the Natural Resources office, assumed the responsibility of maintaining the model and database. Since they had access to ESRI's ArcGIS software, they would update data during each field season and produce maps and reports for a broad audience. The mosquito control team, who are the field experts, used the project products to understand the trends and patterns of their pest control application operations. This also helped them to determine the needs for more data collection and to provide updates on treatment areas, types, and efficacy (post treatment surveys). The assumption in this study is that the Environmental Division team in charge of mosquito control had a basic familiarity with data collection in a GIS fashion for easy integration.

\subsection{Overview of the Rest of this Report}

This project report explains the mosquito control model used to predict potential sites in detail. The following chapters provide more topical details of the project. Chapter Two examines the previous research undertaken in similar or related areas. This provided reference to this study. The chapter gives a general background of mosquito, it life cycle and habitat with more emphasis on the salt marsh mosquito. It looks at past work related to mosquito habitat and model used in regards to this study. Chapter Three outlines the project's system design and analysis. The chapter explains the project plan, deliverables and the technology used as well as software needed. Chapter Four explores the database design of the project. The data used for the project are reviewed in this chapter as to source, migration and treatment. Chapter Five is the project implementation phase. Chapter Six discusses the analysis, results, and overall summary of the project while Chapter Seven describes the conclusions as well as future works as an extension to this project. 



\section{Chapter 2 - Background and Literature Review}

NBVC Point Mugu is about $48 \%$ salt marsh wetland. This salt marsh estuary supports a variety of fauna and flora including mosquitos that undergo a life cycle known as complete metamorphoses, with an immature stage that depends on stagnant water. Stagnant water on the ground, in flood control ditches, and permanent wetlands are very productive mosquito breeding grounds (Kronenwetter-Koepel, Meece, Miller, \& Reed, 2005). This chapter reviews literature related to mosquito life cycle, habitats, health impact, and various programs and methods for mosquito control.

\subsection{Mosquito Life Cycle, Habitats, and Impact}

There are about 3000 known species of mosquitos subdivided into three main types: the salt marsh wetlands mosquitos common along coastal environment, the mountain species, and the fresh water species (Freeborn, 2013). This was also observed by Killeen, Fillinger, Kiche, Gouagna, \& Knols (2002) in their work and was reiterated by Zou, Miller, \& Schmidtmann (2006). Although different in mode of oviposition, these species of mosquitos have a similar life cycle known as complete metamorphoses.

\subsubsection{Mosquito Life Cycle}

Mosquitos lay eggs directly in water, soil and at the base of some plants in places that may fill with water. The eggs can survive dry conditions for a few months. Eggs are hatched in water as emerging "wrigglers" or larva. The length to hatch depends on water, temperature, food and varies with mosquito type.

Mosquito larva live, feed and develop into a third, pupal stage in water. The pupa lives in water but no longer feeds; the mosquitos emerge from the pupal case after two days to a week. The life cycle typically takes weeks but depending on conditions can range from four days to as long as a month. A complete life cycle requires water bodies whether natural, permanent or temporal, fresh or salty. Reproduction is successful as a result of stability of this habitat (Rejmánková, Grieco, Achee, \& Roberts, 2013).

\subsubsection{Mosquito Habitats}

The ecological areas that are inhabited by mosquitos are above-ground stagnant water, flood control ditches, inundated areas, and wetlands. Mosquitos depend on these habitats to complete their life cycle and the habitats vary by mosquito species from fresh to salt marsh. Kronenwetter-Koepel et al. (2005) examined biological and ecological conditions based on mosquito's spatial and temporal distribution, and understanding the characteristics of the ecological niche of mosquitos are critical for mosquito habitat management.

Various environmental variables are used as indicators for the distribution of mosquito habitats. For example Li, Bian, Yakob, Zhou, \& Yan (2009) showed that curvature, elevation, distance to stream or water bodies, and wetness index are the main environmental factors related to mosquito habitats. The salt marsh mosquito's habitats are potential inundated areas as a result of tidal current. Salt water is pushed inland into a lagoon or estuary, causing temporal floods of the low-lying lands along the estuaries or 
lagoons. Salt marsh mosquitos rely on this inundated area to complete their life cycle. Therefore, terrain characteristics and sea level rising surface are important variables to identify temporal flooding areas for salt marsh mosquito's breeding.

\subsubsection{Health Impact of Mosquitos}

The health impact of mosquitos has been extensively studied in the literature because their biting is a nuisance and can transmit diseases to humans and domestic animals (Freeborn, 2013). This conclusion by Freeborn coincided with the work done by Gerry, Ulrike, Ibrahim, Louis, and Bart (2002) who confirmed that mosquitos are carriers of malaria, dengue fever, and West Nile Virus. In addition, Li, Scott, and Edward (2006) found the same results. Kronenwetter-Koepel et al. (2005) study concluded that mosquitos play a major role as vectors in transmission of infectious diseases in the United State and the world. An estimated 120 million people are infected by diseases transmitted by mosquitos globally, with approximately 1.3 billion at risk of infection (GranadosEchegoyen et al., 2014). In the case of West Nile Virus, the Center for Disease Control (CDC) recorded 45 states and the District of Columbia reporting infections in people, birds, or mosquitoes in September, 2016 (CDC, 2016).

Among the three main groups of mosquitos, salt marsh mosquitos are a particular nuisance to the natural ecosystem of Point Mugu. Salt marsh mosquitos transmit pathogens such as the malaria parasite vectored by some of the Anopheles species in Europe and the Middle East, Venezuelan Equine Encephalitis virus vectored by Aedes sollicitans and Aedes taeniorhynchus in the Americas, California group encephalitis viruses vectored by Aedes dorsalis, Aedes caspius, and Aedes melanimon in Europe and western North America, and Ross River virus vectored by Ae. camptorhynchus and Ae. vigilax in Australia (Rochlin, Iwanejko, Dempsey, \& Ninivaggi, 2009). Thus, the salt marsh habitat is of significant public health concern due to mosquito vector species that inhabit this environment.

\subsection{Mosquito Control and Management}

Understanding the breeding grounds and season, as well as their life cycle plays a crucial role in controlling mosquito populations. There have been various mosquito control programs and methods that provide great insight to this project.

\subsubsection{Mosquito Control Programs in the U.S.}

Mosquito control programs have existed for decades in the United States. Baseline data on mosquito diversity and abundance studies date back to the early 20th century. The history of salt marsh mosquito control in California dates back to 1904 along the shore of San Francisco Bay. Fresh water mosquito control followed in 1910, which was as an attempt to control malaria in California and the results turned out positive (Freeborn, 2013).

The preferred techniques in management by most mosquito control experts are water

management, source reduction, surveillance, and other preventive measures as opposed to chemical pesticides that have been frequently used (EPA, 2012). This conclusion is in line with the work of Hayes, Maxwell, Mitchell, \& Woodzick (1985). Application of 
methods with reduced pesticides are encouraged by the Center for Disease Control (CDC) and the Environmental Protection Agency (EPA), wherever they are environmentally sound and effective (EPA, 2012). In doing so, these methods do not put the general public or environment at unreasonable risk from runoff, leaching, or drift when used according to label specification.

The most successful technique is the Larval Source Management (LSM). In the U.S. alone, there are about 743 named mosquito abatement districts that use LSM (Fillinger \& Lindsay, 2011). The mosquito abatement districts bill passed by the legislature of 1915 provided for the formation and organization of tax districts within various counties for the purpose of financing mosquito control (Freeborn, 2013). Success was recorded in California and Florida extensively using the LSM method. In particular, Lee County, Florida's annual budget for mosquito control exceeded \$19 M while in the Metropolitan Mosquito Abatement district the budget was over $\$ 18$ million as a scale of success using the LSM (Fillinger \& Lindsay, 2011).

Other techniques employed to eradicate mosquitos are indoor residual spraying (IRS), using long-lasting impregnated nets (LLINs), and outdoor pesticides application directed against the adult vector population. The World Health Organization (WHO) actively promotes integrated vector management, (integrated pest management in the United States), whereby multiple interventions are combined to control vector-borne diseases (EPA, 2012). Integrated vector management has also been promoted in numerous studies as a follow-up for control activities (Fillinger \& Lindsay, 2011). Large broods of mosquitos originating in salt marshes of tidal wetlands were controlled by draining marsh surface waters (Rozsa, 1995). Tide gates were also used in an attempt to control salt marsh mosquito breeding. However, this was fruitless since it only replaced salt marsh mosquitos with fresh water mosquitos.

\subsubsection{Mosquito Control Using Geographic Information Systems (GIS)}

A spatial approach gained ground when technologies such as remote sensing (RS) and GIS became widely used in 1990s (Rejmánková et al., 2013). Earth observation and measurement from space provided data with spatial and temporal resolutions relevant to mosquito breeding site characteristics. With these data, many RS and GIS technologies can be used to study mosquito habitats.

For example, Bash (2015) discussed how GIS can be an effective tool to address mosquito control. Mosquitos spend a substantial portion of their life cycle in the waterdependent stage. This makes their breeding ground greatly influenced by the environmental surrounding. The estimate of the distribution of species requires two input data sets: the location of the species and the environmental data such as larva habitats, climate data, elevation data, and tide data. First, the locations where the species occurs should be examined to infer the environmental requirements for the species. The requirements of the species are then used to create a map of predicted distribution of the species.

\subsubsection{Modeling Inundation for Mosquito Habitat}

In the context of salt marsh mosquitos, sea level rise affects the extent of saline or brackish water bodies in coastal areas. Using elevation surfaces to model coastal 
inundation areas impacted by flooding and sea level rise is a technique that has been used by scientists to predict inundation (Yunus et al., 2016).

The use of LiDAR data for delineating inundation zones and developing guidelines for risk estimates has become popular in the state and federal agencies (FEMA, n.d.). Planners and researchers rely on elevation base prediction for coastal inundation mapping, thereby modelling the volume of water flow over topography using LiDAR elevation surfaces to determine elevations that are at risk from coastal inundation (Poppenga \& Worstell, 2015). The study also showed that the accuracy of inundation predictions is dependent upon inundation methods. This is exemplified by the hydrologic connectivity of inland and ocean waters in a highly detailed LiDAR elevation surface (Poppenga \& Worstell, 2015).

Using the elevation information, sea level rises can be modeled with approaches ranging from the simple bathtub approach to a modified bathtub approach that takes into consideration both elevation and connectivity. The simple bathtub approach is a singlevalue surface method, which has been used to model inundated areas that are below a specified elevation value without considering hydrological connectivity.

The modified bathtub method forces coastal inundation to occur only where lowlying elevations are hydrologically connected to the ocean (Poulter \& Halpin, 2008). To minimize inundation uncertainties that result from hydrological disconnection raised by features in a LiDAR elevation surface in the single-value surface method, Poppenga \& Worstell (2015) identified hydrological disconnected lands for the consideration of coastal inundation. They found that modeling the spread of flooding from sea level rise or tides changes does not depend on the algorithms of proportioning flow between downslope pixels since inundation is dependent primarily on elevation.

The National Oceanic and Atmospheric Administration (NOAA) Coastal Service Center (2012) also applied a modified bathtub method to map coastal inundation. Their approach accounted for local and regional tidal variability and hydrological connectivity, and considered hydrologically disconnected areas involved in the process of the lagoon inundation. The study showed that coastal inundation monitoring and management were key elements when considering control of salt marsh mosquitos that rely on this areas to complete their life cycle.

\subsection{Summary}

Application of mosquito control can be simplified by understanding the species and its ecological variations. Three types of mosquitos in this study are the salt marsh, the mountain and the fresh water species and although they undergo different modes of oviposition, they all have a life cycle known as complete metamorphoses. The known mosquito breeding habitat are above-ground stagnant water, flood control ditches, inundated areas and wetlands which varies from species to species. This chapter focused on the salt marsh mosquito, looking at their habitats which are inundated areas after high tides. Extensive studies on the health impact of mosquitos showed that the mosquitos are a nuisance and diseases transmitter to both humans and animals.

Mosquito control helps eliminate some of the threats and to perform control, the knowledge of breeding grounds, season, and life cycles are important factor to be considered. Various methods of mosquito control exist. The most successful method in 
the United States was larva source management that controls the population of mosquito larvae.

This chapter looked at the spatial-level approach of modeling potential mosquito breeding sites and introducing them to a database for analytical purpose for mosquito control. Numerous methods were used in predicting potential sites. The model used in this study was adopted from a model used by NOAA for predicting inundation. This model took into consideration hydrological connectivity of the lagoon in predicting inundated areas which are known breeding sites for the salt marsh mosquito species. This study does not take into consideration other factors such as weather and mosquito breeding seasons since the seasons were predefined (NBVC, 2012b). This study focused on the creation of a spatial database and the identification of potential sites for Aedes taeniorhyncus (black salt marsh mosquito) using GIS. 



\section{Chapter 3 - Systems Analysis and Design}

This chapter discusses the system design for the project. Section 3.1 presents on the client's problem statement. Section 3.2 discusses the requirements of the project, broken down into functional and non-functional (technology needed to run the model) requirements. Section 3.3 details the actual design components. Section 3.4 discusses the project plan that was developed for the project, and section 3.5 summarizes the chapter.

\subsection{Problem Statement}

The NBVC Point Mugu recognized the rich ecological diversity of the tidal wetland, and the environmental consequences if standards are not set in place for salt marsh mosquito control. They needed to identify potential breeding sites for salt marsh mosquito larva, using a GIS solution to increase efficiency in survey and treatment, with reduced environmental and public risk. This information would be used to develop an effective strategy plan for controlling the mosquito population within the study area.

\subsection{Requirements Analysis}

Project requirements are a useful structure for drafting, analyzing, and presenting the potential of a system. Client requirements were subdivided into two classes: functional and non-functional. Functional requirements define the structural design of the system. Non-functional requirements define the quality and usability features of the system. These requirements were the initial structure that helped identify, monitor, and analyze the mosquito breeding grounds of the NBVC Point Mugu mosquito control program. Not all personnel who support the mosquito control efforts are experienced in GIS; rather they aid in data acquisition for analysis and pre-planning of control activities. The information product that was generated includes the potential breeding sites, treatment areas, and a system to track effectiveness over time.

\subsubsection{Functional Requirements}

The functional requirements were divided into three primary categories. Table 3-1 lists the functional requirements of the project. The first functional requirement was to identify potential breeding sites. The modified bathtub method was used with other spatial analytical capabilities to determine potential breeding sites. The elevation data used for the analysis were provided by the client, while inundation data were derived using the single-value approach (modified bathtub method) derived from NOAA. 
Table 3-1. Functional Requirements

\begin{tabular}{|c|c|}
\hline $\begin{array}{l}\text { Functional } \\
\text { Requirements }\end{array}$ & Description \\
\hline Geodatabase & The system produced a spatial database \\
\hline Inundation model & $\begin{array}{l}\text { Modified Bathtub method. Elevation and MHHW from tidal } \\
\text { datum using NOAA VDatum were inputs to the model }\end{array}$ \\
\hline Potential sites & Potential layer outputs will be based on inundation level \\
\hline $\begin{array}{l}\text { Track treatment and } \\
\text { survey }\end{array}$ & $\begin{array}{l}\text { System shall allow user(s) to interact and perform some } \\
\text { query and analysis with survey and treatment data }\end{array}$ \\
\hline
\end{tabular}

The second functional requirement was to deliver a spatial database consisting of salt marsh mosquito layers such as potential sites, survey sites, and treatment sites. The spatial database was able to store, capture, query, edit, analyze, and geo-process the data from control activities. The client's spatial database needed to incorporate all field control data, and to monitor and manage them.

The third functional requirement was to track the effectiveness of survey and treatment. This was achieved through capturing the data in a spatial database. Relationships were constructed in the spatial database, and queries built to track the process. The client also required maps of already-treated areas, known hotspots, and potential areas.

\subsubsection{Non-Functional Requirements}

Table 3-2 below outline the non-functional requirements. There were three primary nonfunctional requirements for the project. The first non-functional requirement was the use of ArcGIS 10.3.1 software for Model Builder and the spatial database design that was used to run geoprocessing tools and create the Model Builder for potential sites. The ArcGIS interface was also used for the ArcGIS Spatial Analyst extension necessary to generate the potential sites layers for the project. The system allows data from the model to be appended to the control dataset for continuous monitoring and updates. 
Table 3-2. Non-Functional Requirements

\begin{tabular}{|l|l|}
\hline $\begin{array}{l}\text { Non-Functional } \\
\text { Requirements }\end{array}$ & Description \\
\hline ArcGIS 10.3.1 & $\begin{array}{l}\text { Software for project design } \\
\text { The potential areas were created by converting from raster } \\
\text { to vector }\end{array}$ \\
Documentation & $\begin{array}{l}\text { Documentation of workflow and metadata } \\
\text { System Interface }\end{array}$ \\
\hline
\end{tabular}

The second non-functional requirement was the documentation of GIS tools, metadata and schema of the geodatabase as the end product to be submitted to the client. The client needed to understand the work flow and available data to implement the finished GIS product.

The third non-functional requirement was the system interface. This included the user interface of the system tools for software and hardware working environment and the ideal stage to host the GIS end product, (ArcGIS desktop software version 10.3) such as the minimum hardware requirement for efficiency of the software. This was the requirement for the client to be able to host the end product of the project.

\subsection{System Design}

A system design was created using Microsoft PowerPoint. Figure 3-1 outline the phases involved in the system design and gives an overview of the system architecture. The three phases in the system design are the presentation tier, the user tier, and the data tier. 


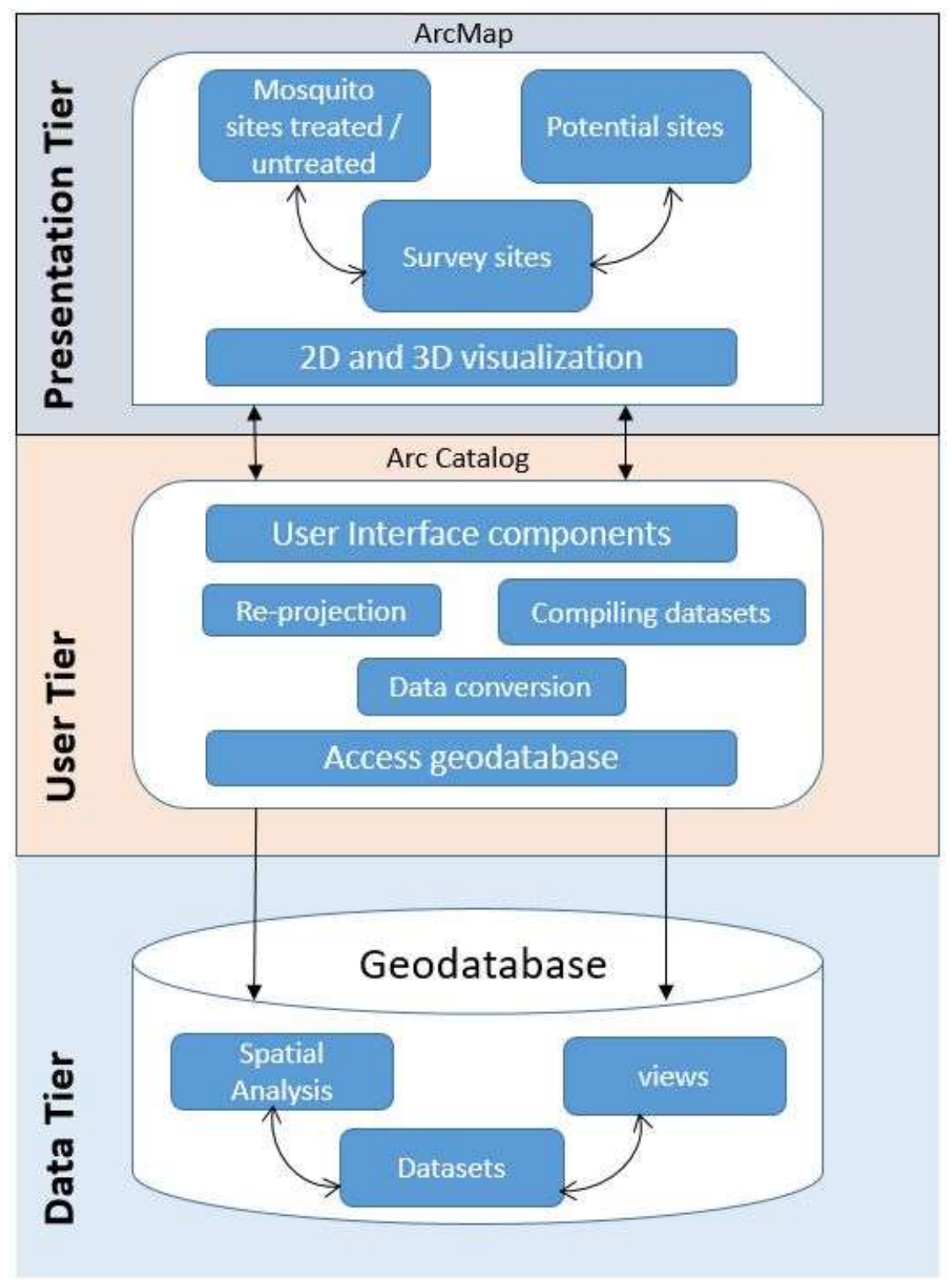

Figure 3-1: System Design

The data tier consisted of compiling datasets from various sources into an Esri file geodatabase. Spatial analysis was done using a hydrologic model and the modified bathtub method (NOAA, 2012) for modeling potential breeding sites (habitats). The potential sites were overlaid with surveyed areas as a test to validate the model. This information was then appended to a dataset in the geodatabase, for which relationships and proximity analysis had been built. This information can be viewed and used in the systematic survey and treatment of breeding sites.

The user processes raw data and arrange them into datasets within the geodatabase for easy access. Data transformation, conversion, and re-projection are performed and assembled in this tier. The Arc Catalog drive the process of dataset re-projection and conversion arranging them in separate datasets within the geodatabase. The presentation tier use data output from the geodatabase and analysis to create $2 \mathrm{D}$ and $3 \mathrm{D}$ visualization of monitoring sites, survey sites and treatment sites maps. 


\subsection{Project Plan}

The project plan was broken down into three phases. The first involved creating a grid of points for the ocean, and extending it to the study area using VDatum within the model extents. VDatum is an online service that converts data from tidal datum to the vertical datum and vice versa. The gridded points were transformed to generate vertical datum of mean higher high water (MHHW) tidal datum from mean sea level. The MHHW values were then used to generate tidal surfaces. The second phase used the digital elevation model (DEM), the tidal surface values and sea level rise values to map inundation. The third process derived potential salt marsh mosquito sites by comparing the inundation and the water flow connectivity.

The first deliverable was a model that allows a user to input tidal datum and set other parameters in dialogue boxes to derive potential sites. These inputs include tide surface or constant and input of sea level rise. The data to run this model were included in the following feature classes of the spatial database: boundaries of NBVC, mosquito surveyed areas, DEM, and grid points from MHHW tidal datum.

The second deliverable was a file geodatabase designed with built in relationships to store, query, analyze, and monitor the mosquito control program. It tracks and stores survey and treatment information that can then be analyzed to see how effective the treatment is. Areas that need more attention and specific types of treatment can be identified.

The third deliverable were maps of NBVC showing mosquito sites and treatment sites. Other deliverables supporting the end products of the project included a text file exploring how to use the model dialog, and a guide of the file geodatabase structure. The guide explains how to run the model dialog, what the outputs represent in ArcMap, and how to visualize the feature class results in ArcMap. Details on how to use VDatum and ensure proper vertical transformation were also included.

\subsection{Summary}

Chapter Three detailed the system analysis and design components of the project, reiterated the problem statement, and identified functional and non-functional requirements, a system design plan, and a project plan. Functional requirements establish the predictive analysis of the model for potential sites generation, while non-functional requirements cover the technical aspects needed to run the model. These include Esri's ArcGIS software, the ArcGIS Spatial Analyst extension, and the necessary hardware specification. The system design aspects of this chapter detailed the geoprocessing model and the data needed for the process. User input constants based on prediction of sea surface changes to get inundated areas that potential areas can be mapped. Finally the project plan detailed the overall strategic goal for accomplishing the project. 



\section{Chapter 4 - Database Design}

Building a spatial database for this project to record, store and manage data was one of the major functional requirements. This chapter focuses on database design and data collection. The first two sections describe the conceptual and logical data models. Data sources and acquisition methods are explained in sections 4.3 and 4.4. Section 4.5 describes data scrubbing and the chapter ends with a summary.

\subsection{Conceptual Data Model}

The conceptual data model explains the entities and their relationships relevant to this project. Figure 4-1 illustrates the conceptual data model of salt marsh mosquito control. Three main entities including monitoring sites, survey points, and treatment locations, are included in the conceptual model.

There are different types of monitoring sites, which is related to the physical feature of the area, be it tidal driven, temporarily flooded, or permanently flooded. Each site may be surveyed or treated. Survey captures new mosquito locations, monitoring the assessment of prior observations, and potential sites. Treatment points are recorded with information such as types of treatments, and location of treatments.

The survey points and the treatment points are inside the monitoring sites. The relationship of the monitoring site to treatment is a one-to-many because multiple treatments can be conducted in one monitoring site. One monitoring site can have many survey points. The association between survey points and treatment area is zero-to-one, because a survey point may or may not be treated. The agent tracks the survey and treatment of when the point was surveyed or treated. 


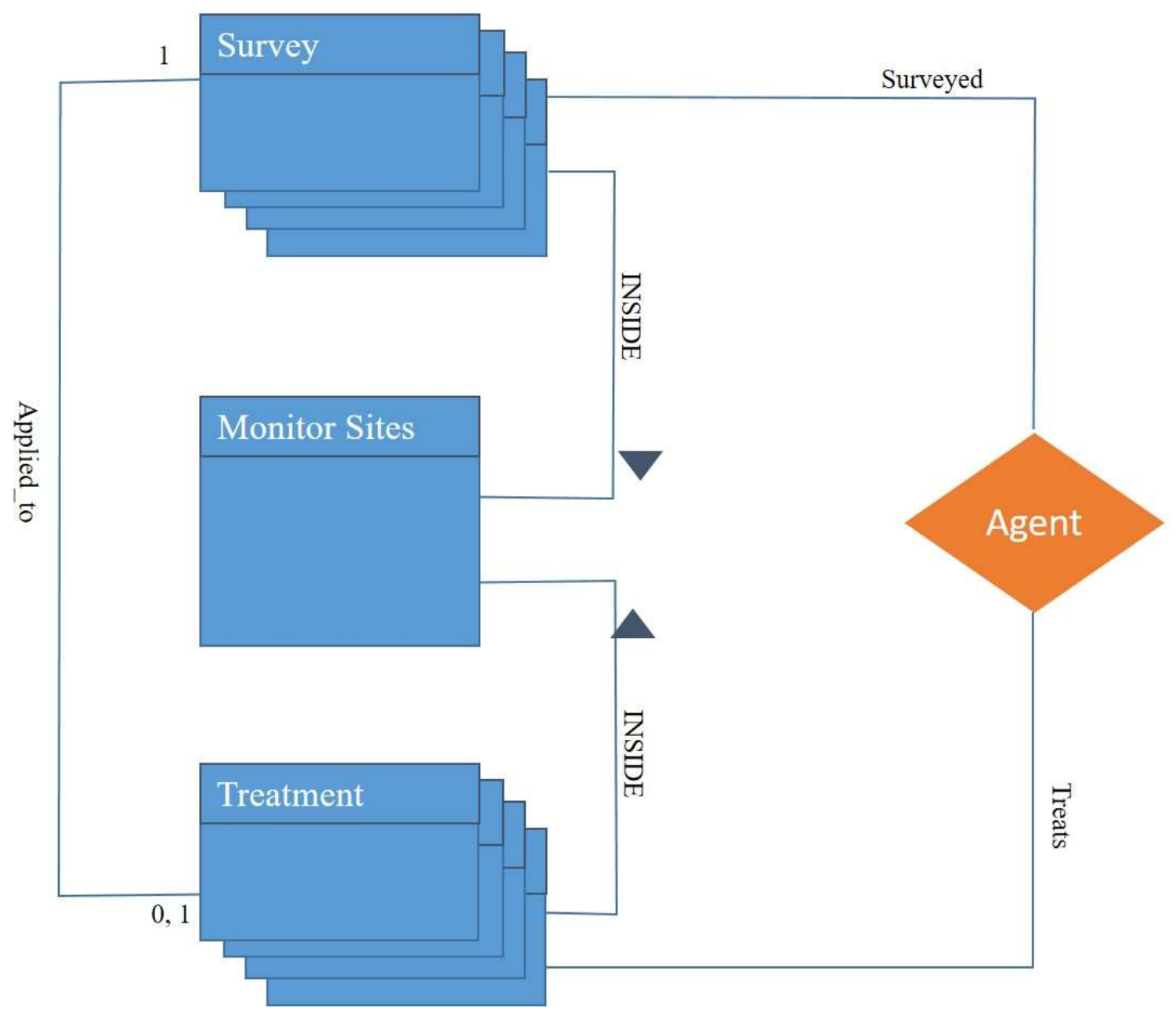

Figure 4-1: Conceptual Data Model

\subsection{Logical Data Model}

The logical data model is the realization of a physical geodatabase design from the conceptualized model. It helps a conceptual model transferred to a physical model. The logical database model designed for this project was the object-oriented relational database. It allows data to be stored and manipulated effectively to create the information product for this project. The ArcGIS file geodatabase extends the structure of the relational model with some capabilities of the object oriented model by adding an abstract data type. A file geodatabase was designed for the project with data storage capacity that can scale up to one terabyte per feature class.

The logical data model for the project, shown in Figure 4-2 illustrates the data structure of the project's geodatabase named NBVC_EDoPWD.gdb. The data were organized into four vector feature datasets, a table of attributes, and two raster datasets. The standalone table is Mosquito Monitoring Site Attribute Information (MonSitesToMonTable), which includes site name, location, and larvae count. The feature datasets, the raster datasets and the standalone table were the key set of data on 
which analysis was performed to track, store, and capture all necessary information for effective control, monitoring, and management of salt marsh mosquitos.

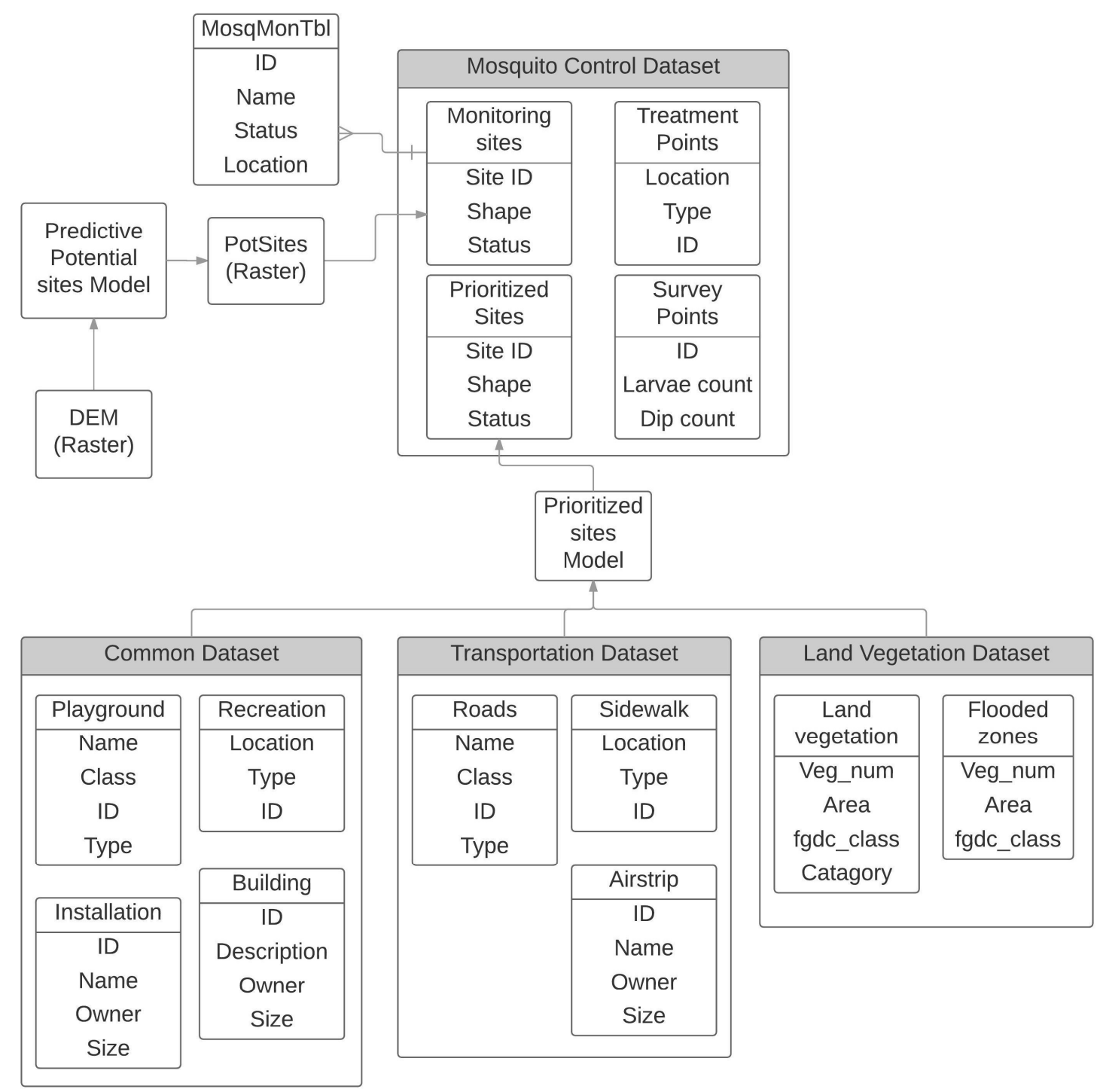

Figure 4-2: Logical data model showing the physical geodatabase design

The Mosquitos Control Feature Dataset includes the monitoring polygon feature class (MosqMonSites), the treatment point feature class (MosqTrtSites), the survey point feature class (MosqSvySites), the prioritized sites polygon feature class (PrioritizedSites), and relationship classes. The monitoring polygon feature class contains a unique ID and subtype. The subtype indicates whether this monitoring site is already existed. The "monitoring" value means it was hand-drawn by the client, while the "potential" values indicates this is a potential sites predicted in the project. The mosquito survey feature class captured breeding site information, including locations and a unique ID. The mosquito treatment feature class captured treatment type and other attributes with a 
unique identifier. The prioritized sites feature class is the output from the proximity model that was developed in this project. MonSitesToMonTable is a one-to-many simple relationship of mosquito monitoring sites and the mosquito monitoring table stored in the geodatabase. The mosqmnsitestomosqsvypts is a simple relationship between the mosquito monitoring site and the mosquito survey points feature class. The mosqmnsitestomosqtrtpts is a one-to-many simple relationship of the mosquito monitoring sites and mosquito treatment points. Agent_asssociation is an association that keep track of the agents that perform survey and treatment.

The Common Feature Dataset contains eight feature classes: Buildings, Installation Boundary, Playground, Recreation Area, Shoreline, Structure, Wall, and Water features. The Transportation Feature Dataset includes AirfieldMarkings, Airfield Marking polygon, Airfield Section, Bridge, Road Center Line, Road Section, and Sidewalk.

The last one is the Land Cover Feature Dataset that contains two feature classes: vegetation cover polygons and a derived polygon feature class of flooded areas. The Land Cover Feature Dataset was selected to best represent the environment where the mosquito thrives. The vegetation cover feature class describes the land class types, such as tidal marshes and intermittent floods that mosquitos are likely to thrive. Other land cover types contained are temporal flood and sea flood. The flood zones feature class was derived from the vegetation cover feature class, which includes tidal marshes and intermittent floods.

The raster feature datasets include the digital elevation model and the potential breeding sites. The potential breeding site raster is the output from the predictive model that was developed in this project.

\subsection{Data Sources}

The data source for this project was the client. The NBVC Point Mugu provided the datasets in the form of map packages that have reference layers, thematic layers, digital elevation models (DEM), and a high resolution image of the area. The package came as an ArcGIS Map Package with two ArcGIS Map Documents of NBVC Point Mugu features.

The ArcGIS Map Package has two geodatabases: the first one has 16 feature classes divided into two feature datasets and the second one has two feature classes, an MrSID image, a DEM, and a standalone attribute table about the monitoring sites. Mosquito monitoring sites point and polygons were collected and built by the client. Infrastructure and land vegetation were from the Point Mugu Integrated Resources Management Plan (INRMP), a subcontractor for mapping NBVC facilities. Figure 4-3 shows the infrastructural data for NBVC Point Mugu. 




Figure 4-3: Map of Infrastructure and hydrology from client's dataset

The vegetation cover feature layer (illustrated in Figure 4-4), helped to identify potential salt marsh sites based on land cover type. 


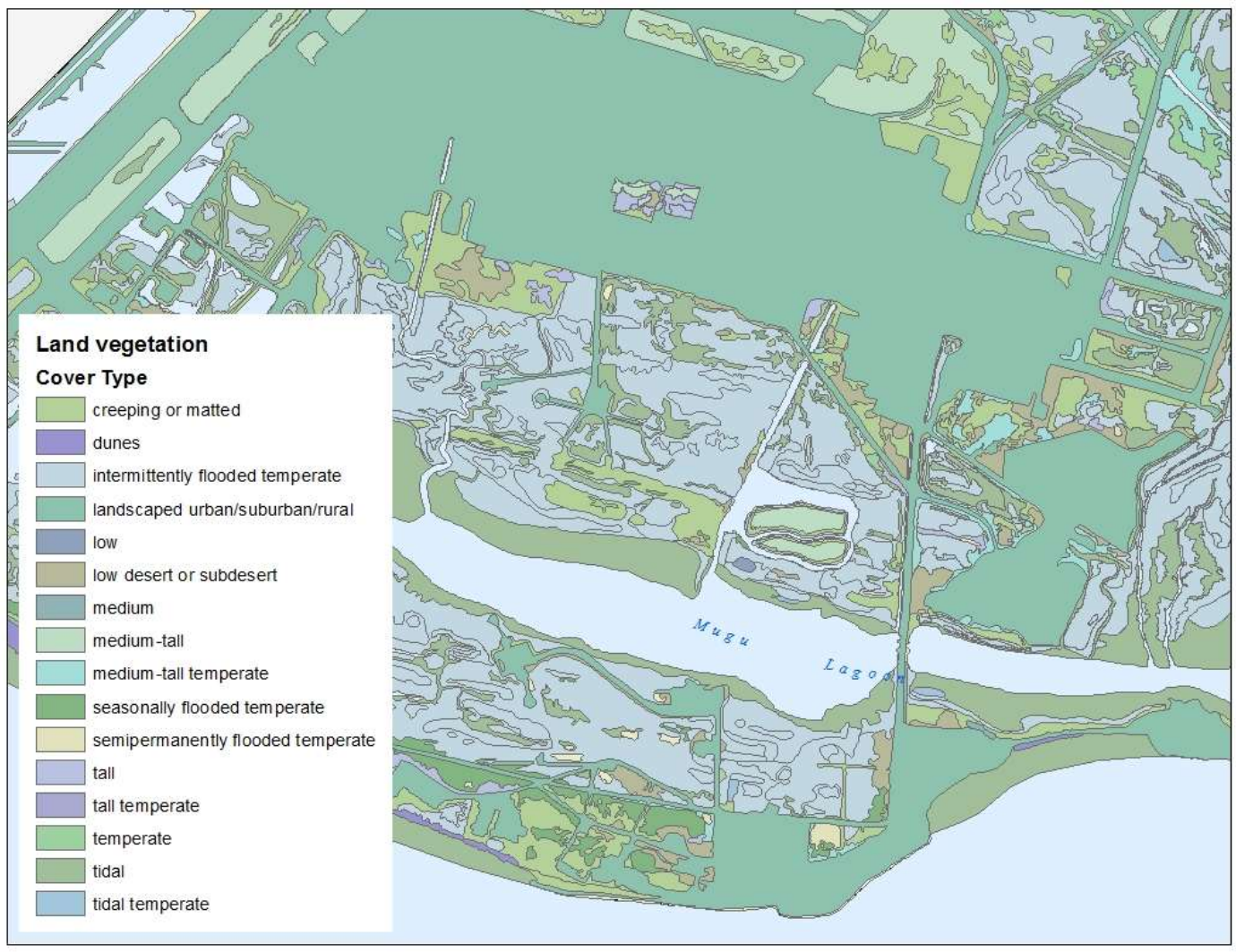

Figure 4-4: Land classes

The 3.2 feet resolution DEM was an Esri-derived LiDAR elevation dataset for Point Mugu naval base. Figure 4-5 presents the digital elevation model of Point Mugu. 


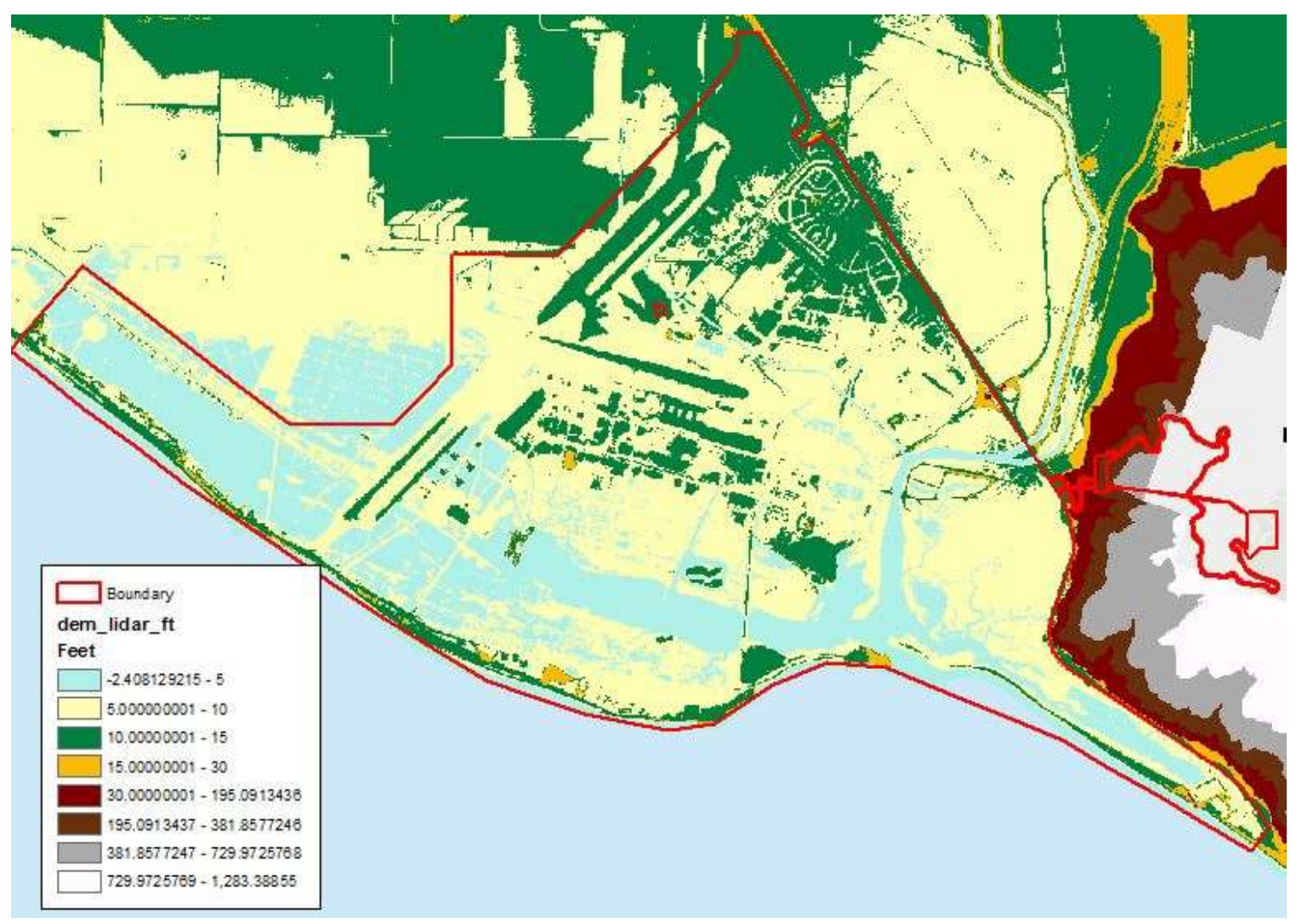

Figure 4-5: Digital Elevation Model

The Point Mugu wetland is a low lying area with typical elevation range of about four to thirteen feet above sea level. The elevation ranges in this wetland are impacted differently by changes in the water level. The impacted areas of concern were the low marsh and high marsh of elevation ranging three to nine feet. Low marsh and high marsh are regularly flushed by the rise and fall of tides. The areas that are potential breeding sites are mostly the high marshes that do not have a regular current after high tides. They are mostly sinks that will not drain easily back to the channels, unlike the low marshes' living ponds.

The Map document and supporting spatial data for NBVC Point Mugu mosquito monitoring sites were in the Metadata format of ArcGIS 1.0 and the Metadata style was FGDC CSDGM Metadata. Data were provided in the WGS 84 geographic or the California State Plane Coordinate (SPC) Zone V coordinate systems. For this project, all datasets were maintained in the California SPC Zone V coordinate system.

\subsection{Data Scrubbing and Loading}

The map package was unpacked and opened in ArcCatalog 10.3.1 and the layers and feature classes were examined in ArcMap. The map package contains three file geodatabases, two images (LiDAR image and high resolution satellite image), and a table of attributes. The data were reviewed to determine their relevance. The Esri ArcMap and Esri ArcCatalog software were used to scrub and load the data. 
A new file location was created and the related feature classes of interest were loaded to the created file geodatabase. The feature class attributes were reviewed and the null fields were excluded during data loading into the geodatabase. Figure 4-6 shows the datasets that were created and incorporated into the file geodatabase. The file geodatabase was composed of a mosquito control dataset, common dataset, transportation dataset, land cover dataset, and a mosquito control toolbox. Various feature classes are stored in each feature dataset as described in Section 4.2. The models utilized in this project were created and stored in the mosquito control toolbox.

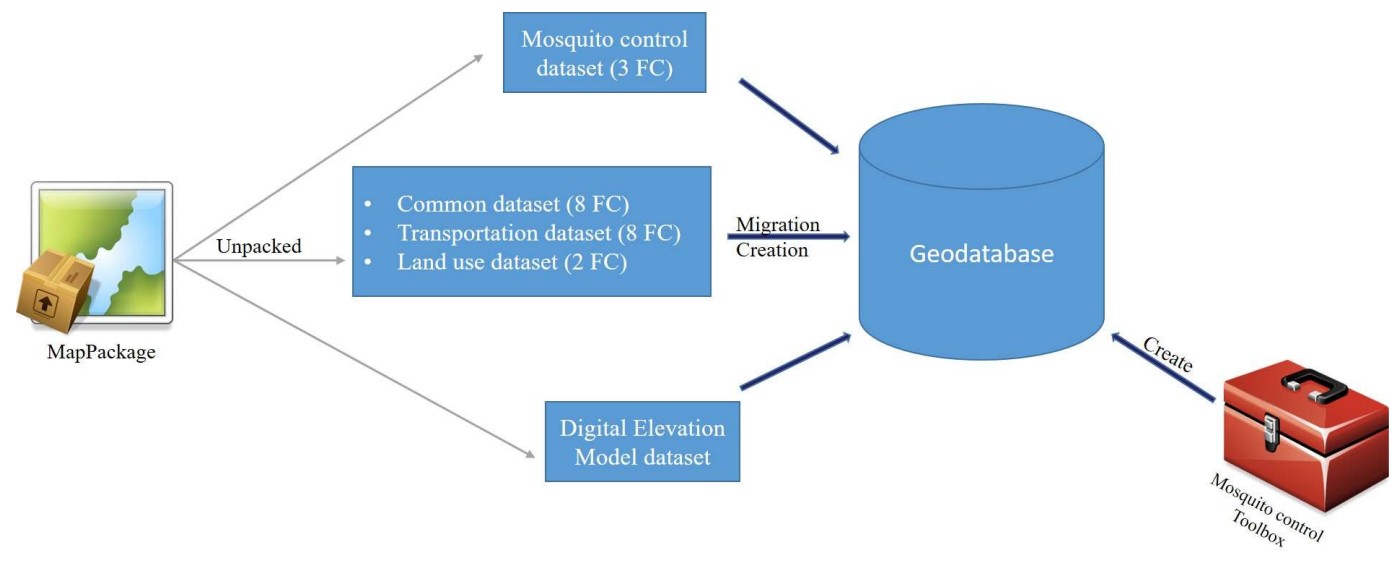

Figure 4-6: Data migration, creation and organization of the spatial database

The detailed process of migration and creation of each of the datasets is broken down in the workflows illustrated in the following figures. Figure 4-7 represents the process of organizing and building the mosquito control dataset.

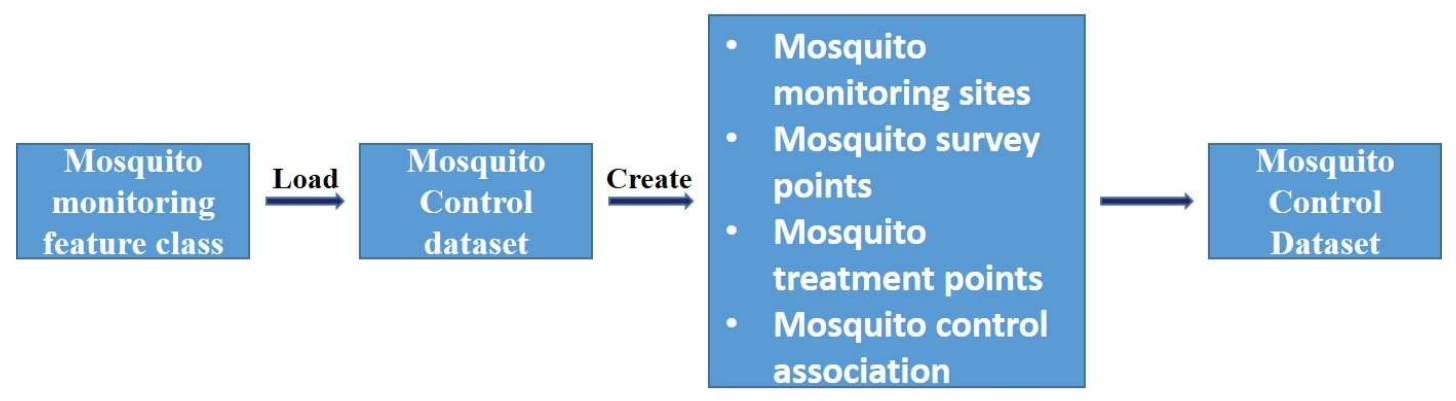

Figure 4-7: Process of creating the mosquito control dataset

Other feature datasets necessary for the project were migrated into the file geodatabase. Figure 4-8 shows the process of loading and creating datasets necessary for analysis and the basemap. This involved loading and organizing the provided data into various datasets. The key data involved included the transportation, land cover, infrastructure, and the DEM. 


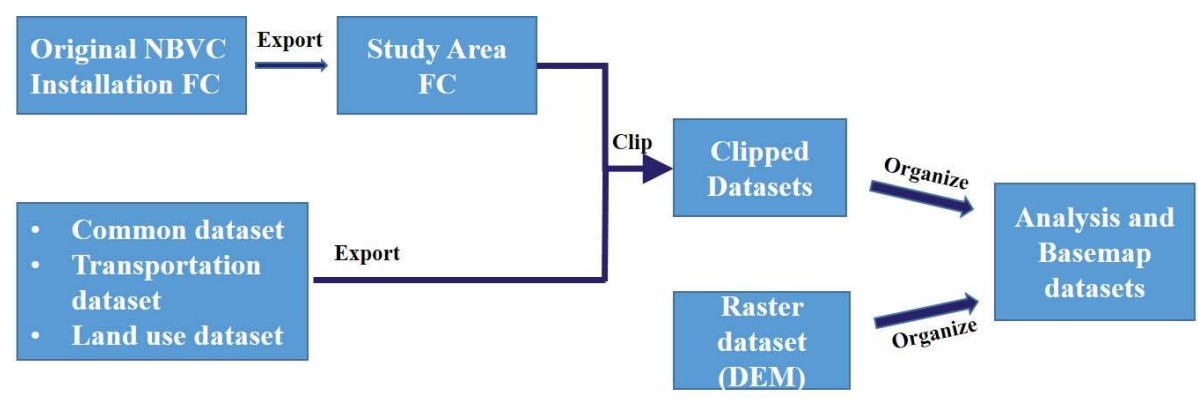

Figure 4-8: Process of migrating datasets necessary for analysis and basemap

The land vegetation class dataset contained many null fields. The dataset was comprised of 1765 records with 17 classes. A new field was created containing records relevant to the project. This field narrowed the classes to five as shown in Figure 4-9. This attribute classified the site based on the types of landform required for this project.

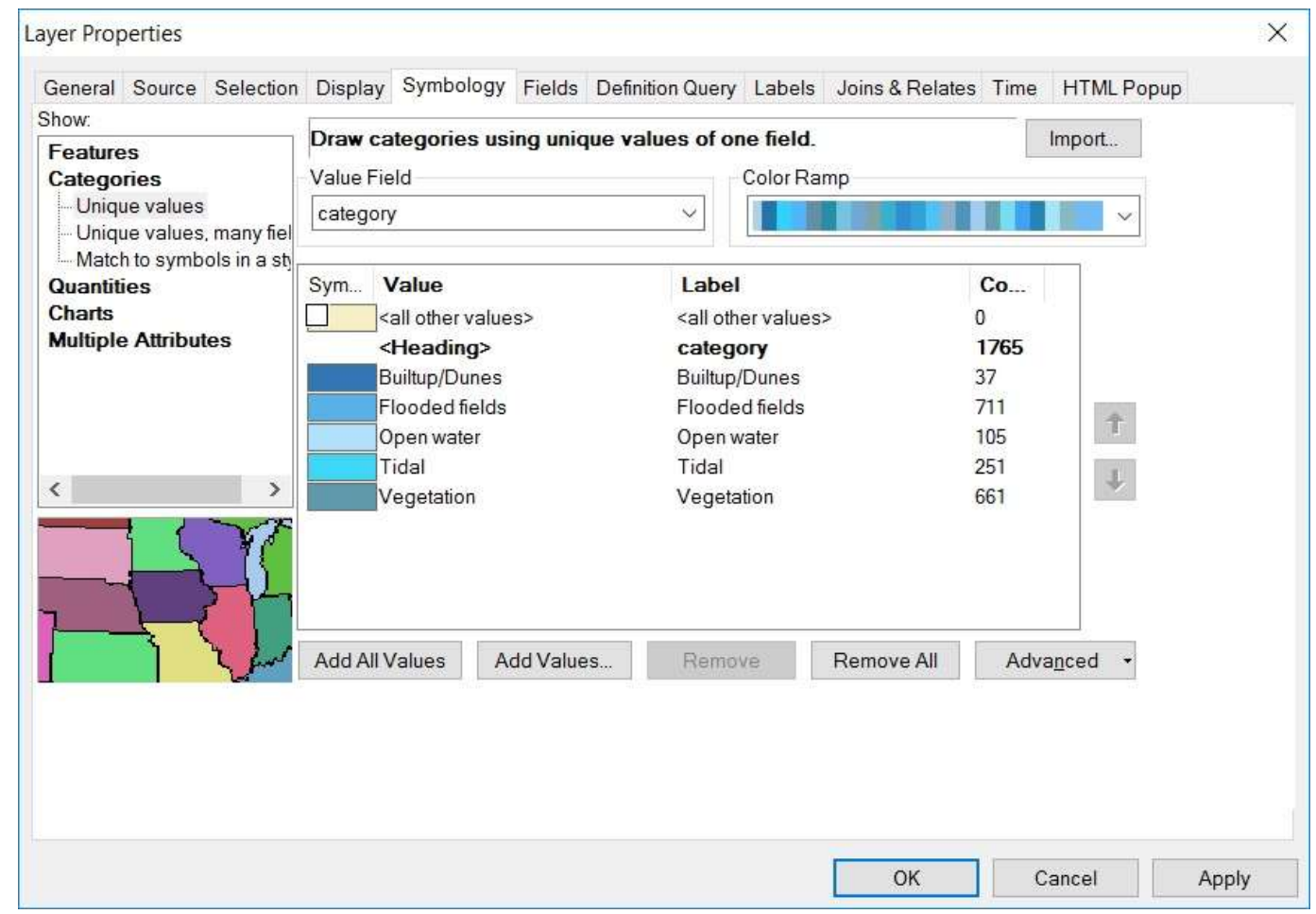

\section{Figure 4-9: Categories of land cover classes}

The potential sites model was created and stored as a tool in the file geodatabase. The datasets included other NBVC facilities and thus were clipped to the study area in the process of scrubbing and loading. This was to ensure that null data fields, fields not relevant to the project, and unknown locations were deleted to create efficient datasets. Scrubbing and loading of the DEM was required for this project considering that the DEM was the main input for the model.

The datasets provided for this project did not include key data in determining potential breeding sites such as tidal trends of the study area. After consulting the client 
and researching on similar topics, the approach to get tidal data for an average estimation of potential sites based on the mean of higher high water levels in this area was used. Data screening was performed and redundant data cleaned to match required project specifics.

\subsection{Summary}

This chapter detailed the database design to store, organize, and manage data required for this project. The conceptual and logical data models of this project were outlined in this section, including the data sources used and data scrubbing and loading. The conceptual database design implemented entities and their relationships of mosquito monitoring sites, survey sites, and treatment sites into the data model. The logical model in this project implemented feature classes, relationships, and a model builder in the file geodatabase that is modified each time the model is being run. The data model displayed the steps, input, and processes involved. The datasets used in this project were provided by the Environmental Division of Public Work, NBVC Point Mugu. The tidal surface was a derived product from a point grid of the study area. The tidal surface was almost a flat surface which was averaged and used as a tidal surface value within the model. Data scrubbing and loading were required to reduce undesirable attributes within the dataset. 


\section{Chapter 5 - Implementation}

The key components to be constructed for the project were a file geodatabase for data storage, a proximity analysis, and a prediction model of potential mosquito breeding sites. This chapter looks at the creation of some of these elements and the challenges encountered during development. The software used was Esri's ArcGIS version 10.3.1. A grid point text file was used to generate a tidal surface from a triangulated irregular network (TIN). ArcGIS ModelBuilder was used to create the model. This was stored in a toolbox within the file geodatabase.

\subsection{Predicting Potential Breeding Sites}

The potential salt marsh mosquito breeding sites are located in the inundated areas after high tides that do not drain easily to the connected drainage of the study area. This project predicted such areas using the modified bathtub approach in conjunction with other Spatial Analyst functions. The modified bathtub approach is a technique used by NOAA to predict areas that will be flooded from sea level rise (NOAA, 2012). Figure 5-1 outlines the workflow for predicting potential salt marsh mosquito breeding sites, which involves four steps: generating tidal surface, generating inundated areas, generating Point Mugu lagoon drainage, and generating potential breeding sites.

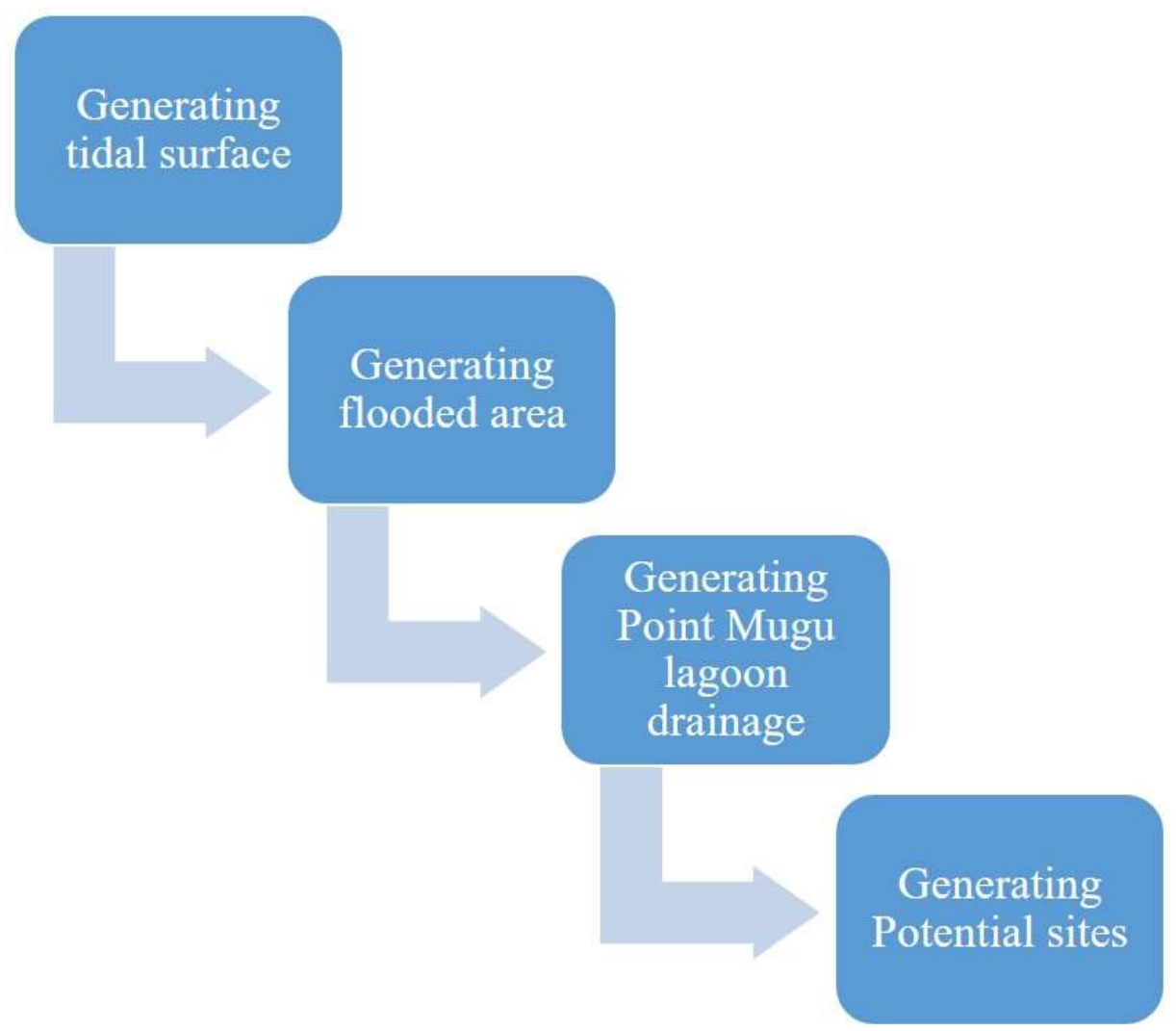

Figure 5-1: Workflow of the predictive potential sites model 
Two datasets were used which are the digital elevation model (DEM) and the tidal surface. By comparing the tidal surface with the DEM, the flooded areas were extracted. Since the breeding grounds are the areas where static water can hold, the drainage in the study area was removed from the flooded areas resulted from high tides. The final output was the potential breeding sites. The following sections detail the entire process.

\subsubsection{Generating Tidal Surface}

A tidal surface is a surface depicting elevation or height of water surface; it is derived from tide heights. Tide heights have a different datum from DEM. Tide heights are measured with different tidal datums while DEM heights are measured from the mean sea level (MSL), also known as the vertical datum. The elevations of the tidal datums are referenced to the station datum and are measured in feet. The station datum is unique for each station and is a fixed base elevation to which all water level measurements are referred. MSL is a tidal datum determined over a 19-year National Tidal Datum Epoch that pertains to local mean sea level.

The vertical datum used in this case was the North American Vertical Datum 1988 (NAVD88) fixed datum derived from a simultaneous, least-squares constraint adjustment of the local mean sea level. NAVD88 is the national standard geodetic reference for heights (NOAA, 1990). Figure 5-2 show the different points of reference for the DEM and tide height. The elevations of the tidal datums are illustrated in the figure. 


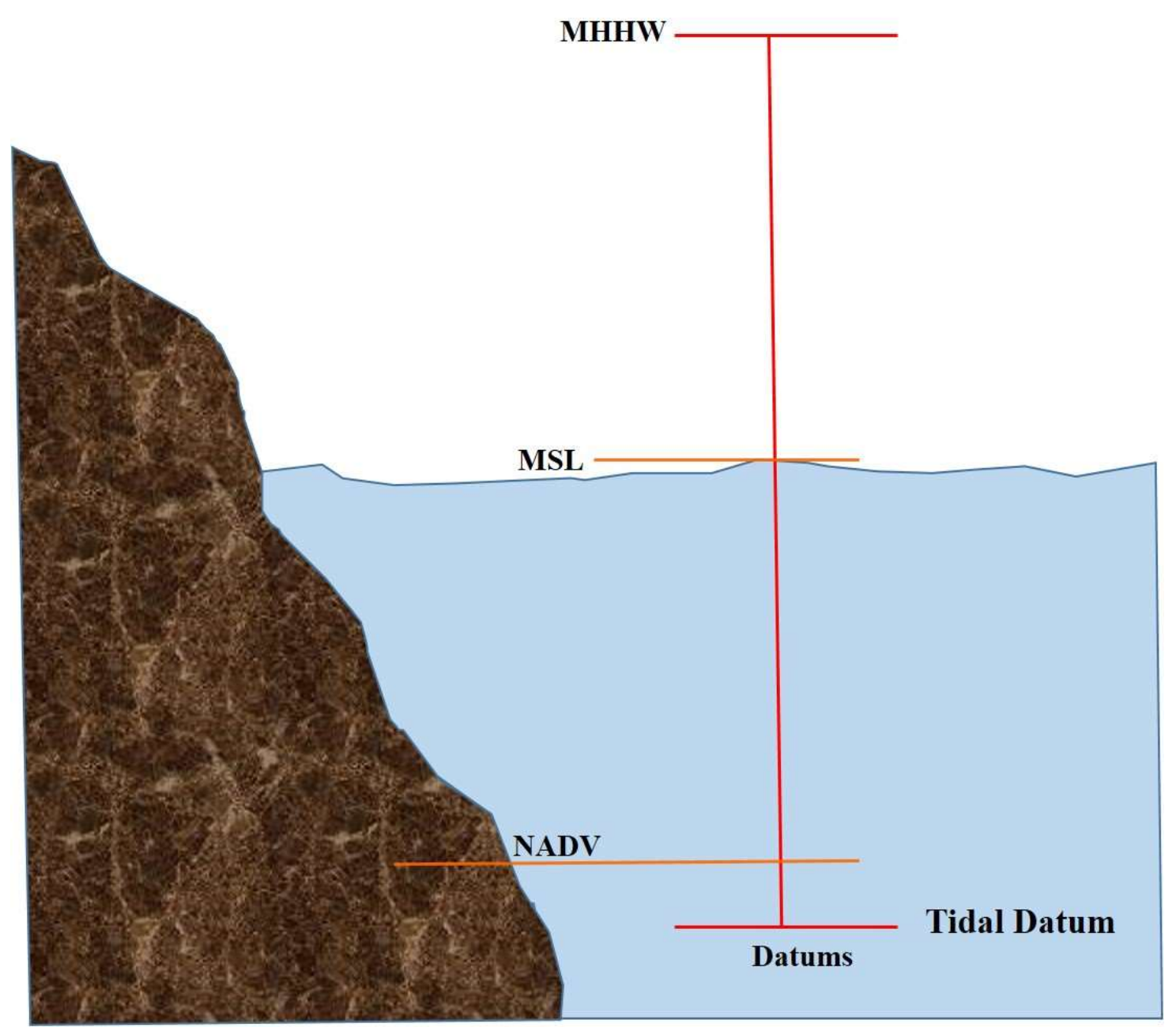

Figure 5-2: Reference point for tidal height and DEM

The mean higher high water (MHHW) is the average highest elevation of the tidal surface over the National Tidal Datum Epoch. This measurement was used to estimate the tidal surface for predicting potential breeding sites. Figure 5-3 displays the workflow for generating the tidal surface.

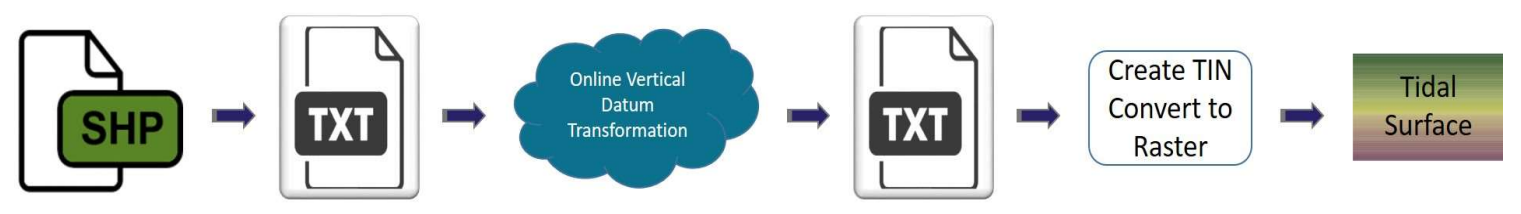

Figure 5-3: Workflow for generating tidal surface

First, a shapefile of a grid of points was created over the study area with a fishnet spacing of 500 meters (1500 feet) and converted into a point text file. This text file format as illustrated in Figure 5-4 (a) with zero z-values was then processed by an online tool to generate the points' elevation. 


\begin{tabular}{|l|l|}
\hline fishptsVD1.txt-N... $-\quad \square \quad \times$ \\
File Edit Format View Help \\
\hline POINT_X,POINT_Y,POINT_Z \\
$-119.160,34.060,0.000$ \\
$-119.155,34.060,0.000$ \\
$-119.150,34.060,0.000$ \\
$-119.144,34.060,0.000$ \\
$-119.139,34.060,0.000$ \\
$-119.134,34.060,0.000$ \\
$-119.128,34.060,0.000$ \\
$-119.123,34.060,0.000$ \\
$-119.118,34.060,0.000$ \\
$-119.112,34.060,0.000$ \\
$-119.107,34.060,0.000$ \\
$-119.102,34.060,0.000$ \\
$-119.096,34.060,0.000$ \\
$-119.091,34.060,0.000$ \\
$-119.086,34.060,0.000$ \\
$-119.080,34.060,0.000$ \\
\hline
\end{tabular}

(a)

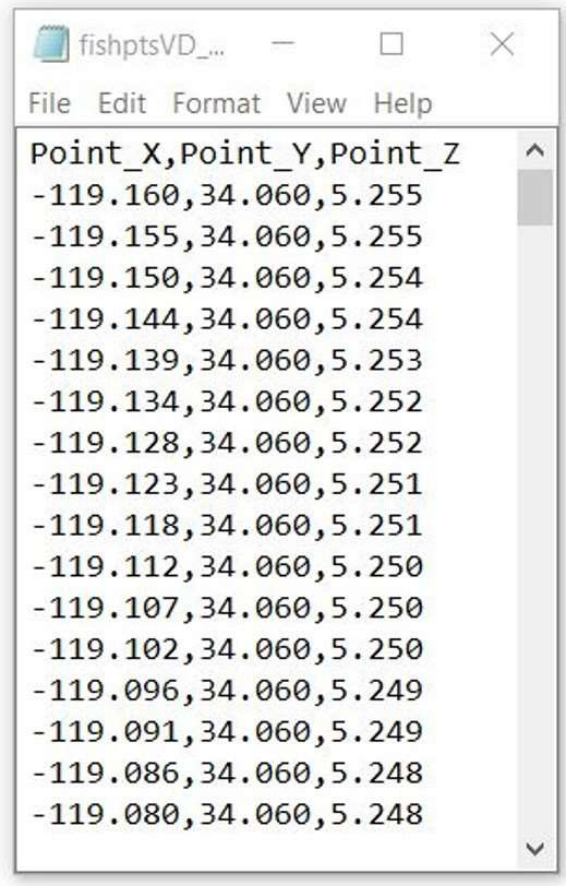

(b)

Figure 5-4: Grid point text file before and after transformation

The online Vertical Datum transformation tool

(http://vdatum.noaa.gov/vdatumweb/vdatumweb?) takes the input and output a text file with z-values of the mean higher high water transformed value as shown in Figure 5-4 (b). The target unit was set in the transformation tool to U.S. foot to support the State Plane Coordinate system used in the project. Figure 5-5 is the tool interface used to generate $\mathrm{z}$-values of the tide heights referenced to vertical datum. 


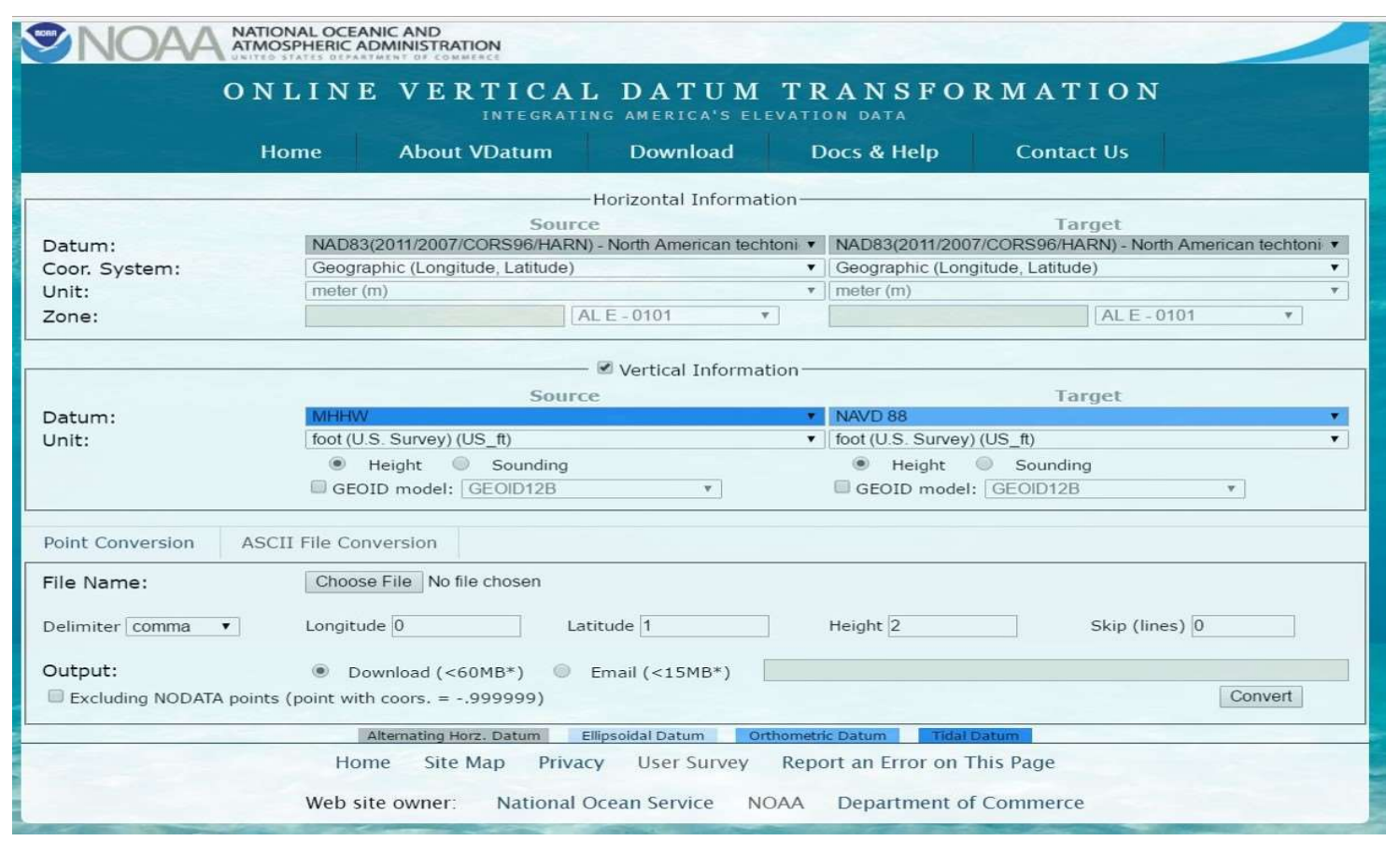

\section{Figure 5-5: NOAA online transformation tool interface}

A TIN of the tidal surface was then generated using the z-values and then was converted to a raster of tidal surface using the TIN to Raster function in ArcGIS. Examining the tidal raster, it was found that the tidal surface elevation did not vary much for the study area, ranging from 5.240 to 5.270 feet $(159.7152 \mathrm{~cm}$ to $160.6296 \mathrm{~cm})$. This margin of 0.03 foot, when compared with that of the elevation data of the Esri LiDAR derived DEM of approximately $15 \mathrm{~cm}$ (0.49 foot), was negligible. As such, the tidal surface was deemed as a flat surface of 5.2 feet. However, if the study area would be large and the tidal surface variation is significant, a tidal surface should be used.

\subsubsection{Generating Flooded Areas}

To generate the flooded areas, the modified bathtub approach was used with a combination of morphological open operator. Figure 5-6 shows the workflow.

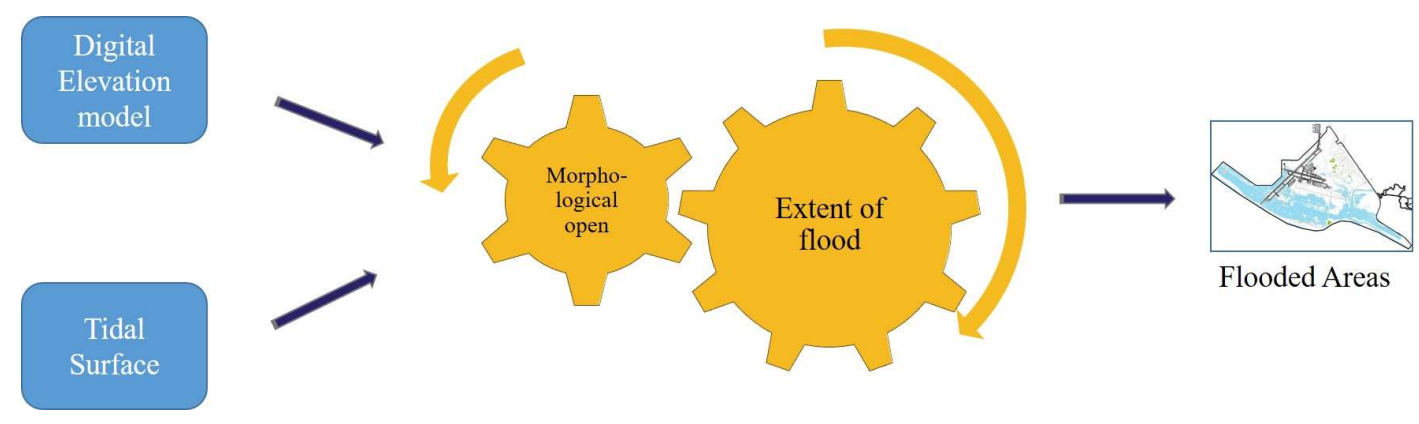

Figure 5-6: Workflow for generating flooded areas 
The modified bathtub method compares the elevation of the terrain to the tidal surface and identifies all the areas below the tidal surface. These areas are the flooded areas. Spatial Analyst extension of ArcGIS is required for this process. First, the map algebra was applied to identify the areas that are below the constant tidal surface of 5.2 feet. Figure 5-7 shows the raster calculator interface from the Spatial Analyst. The condition expression was used for that purpose. The output raster contains two values: 1 representing the flooded areas while 0 representing the areas above the tidal surface.

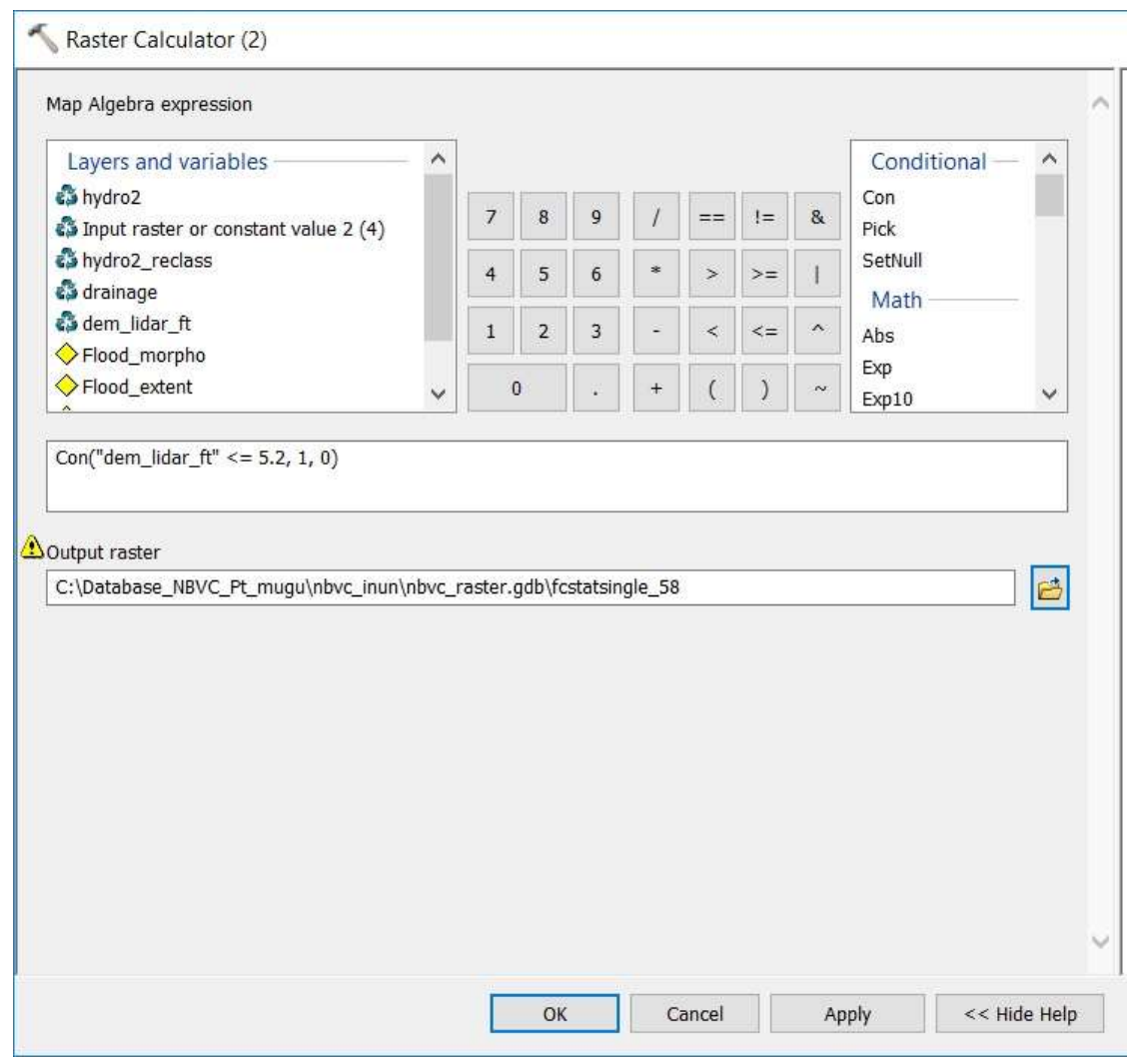

Figure 5-7: Conditional Expression in Raster Calculator

After the flooded areas were extracted from the DEM, the morphological open operator was applied to remove the noise in the raster. First, a minimum focal statistics was applied based on a 3 by 3 neighborhood (Figure 5-8). The isolated small inundated areas were then removed. To regrow other inundated areas back, the maximum focal statistics was applied. 




\section{Figure 5-8: Focal statistics interface}

\subsubsection{Generating Drainage of Point Mugu Lagoon}

After the flooded areas were identified, it was necessary to eliminate the drainage from the flooded areas because the drainage is not likely to become potential breeding sites due to constant flows. Although some water features are included in the client's dataset, the water features are not complete. Therefore, water channels were extracted based on the elevations of water surface. Generating drainage followed a workflow as indicated in Figure 5-9.

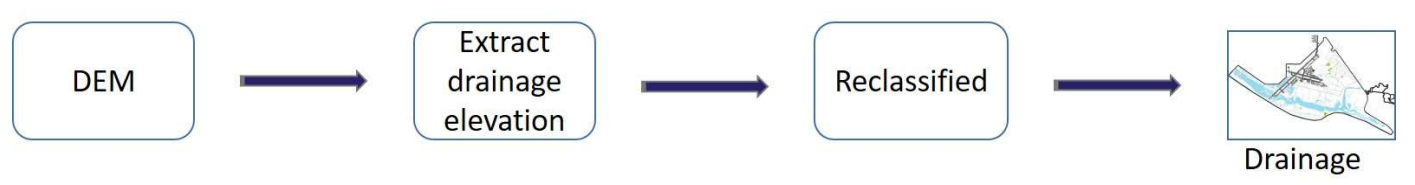

\section{Figure 5-9: Workflow to generate drainage}

The process involved extracting the drainage channels from the DEM. First, the elevation of water channels was measured on the DEM for the water features. The result shows that the water channels are approximately 4.7 feet high. Using this as the threshold, the condition expression was applied to extract the pixels from the DEM that are water channels. The output was a binary raster layer with 1 representing the water and 0 indicating land. The output was further reclassified to switch the values of water and 
land. In doing so, the land pixels have the value of 1 and water pixels have the value of zero.

\subsubsection{Generating Potential Sites}

Once the flooded areas and drainage were built, the next step was to identify the potential sites by removing the drainage from the flooded areas. This is illustrated in Figure 5-10.

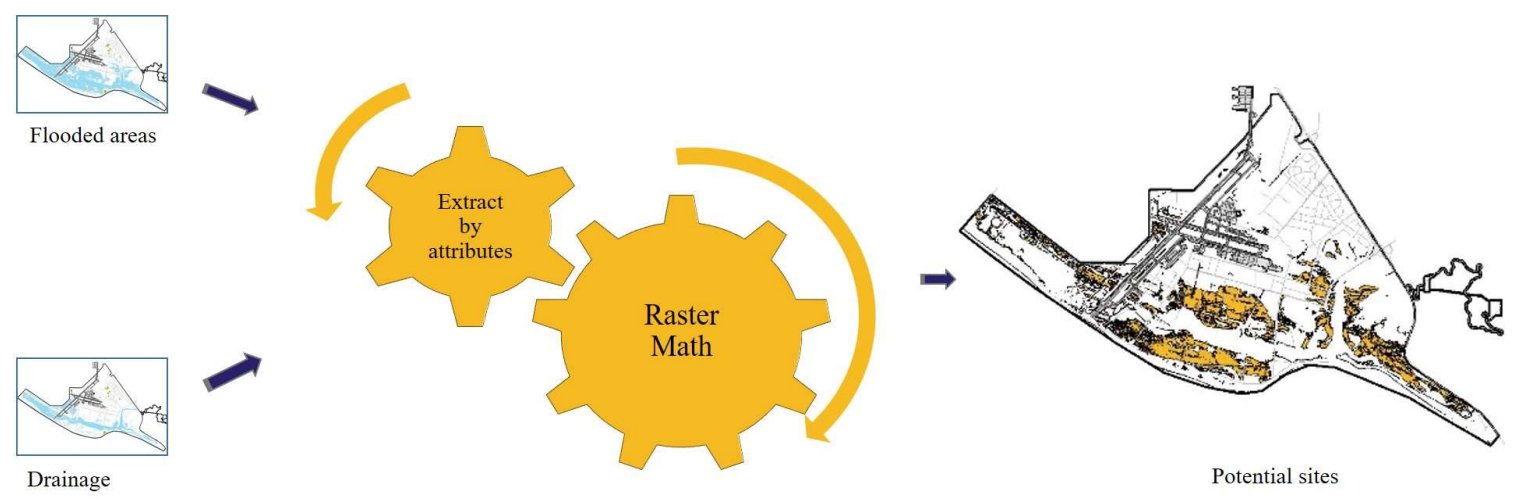

Figure 5-10: Workflow generating potential sites

Map algebra was applied with the multiplication operation to the two input rasters. Since the drainage pixels have the value of zero, all flooded areas that pass through the drainage will take a final value of zero after the multiplication. The extract by attributes tool extracts the cells of output raster from the raster math function based on a logical query corresponding to potential sites which have cell values of one. The final output shows the potential breeding sites that are below the tidal surface and not connected to the drainage in the study area.

To integrate the potential areas with other datasets for more analyses, eighteen polygons were digitized from the predicted potential breeding areas to form recommended monitoring sites. The vegetative cover was used to identify location that are prone to mosquito breeding. The polygons were within the land vegetation cover of tidal and flooded fields. These eighteen polygons were then added to the original monitoring sites feature class for the proximity analysis, which will be explained in Section 5.2.

\subsubsection{Building an Interface for Generating Potential Breeding Sites}

The aforementioned sections explained the procedures involved in predicting the potential breeding sites. To facilitate the client's future analysis, a model was constructed with the ModelBuilder application in ArcGIS. The model diagram is included in Appendix A. The model was stored in the file geodatabase.

Figure 5-11 shows the interface that the user can use to predict the potential breeding sites. The input includes DEM, drainage and tidal values, and the user can change the threshold values for tidal surface and drainage. Once the tool runs, the output includes two raster: one is the flooded areas and the other one is the potential sites after considering the drainage. 


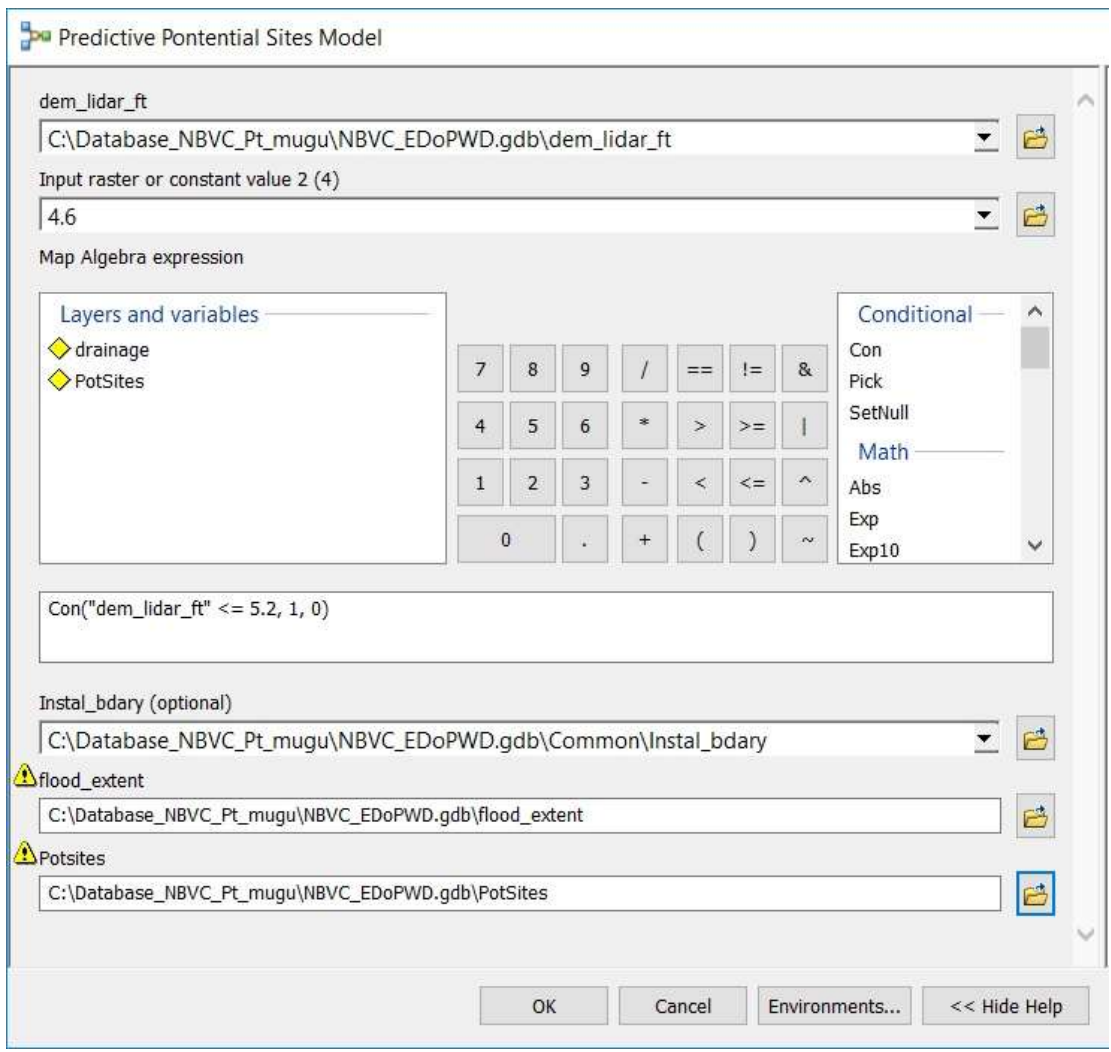

Figure 5-11: Predictive potential sites interface

\subsection{Proximity analysis of prioritized sites}

To help the client to prioritize their survey and treatment locations, a proximity analysis was conducted to identify the monitoring sites that are close to outdoor activities, such as playground, recreational areas, and residential areas. 


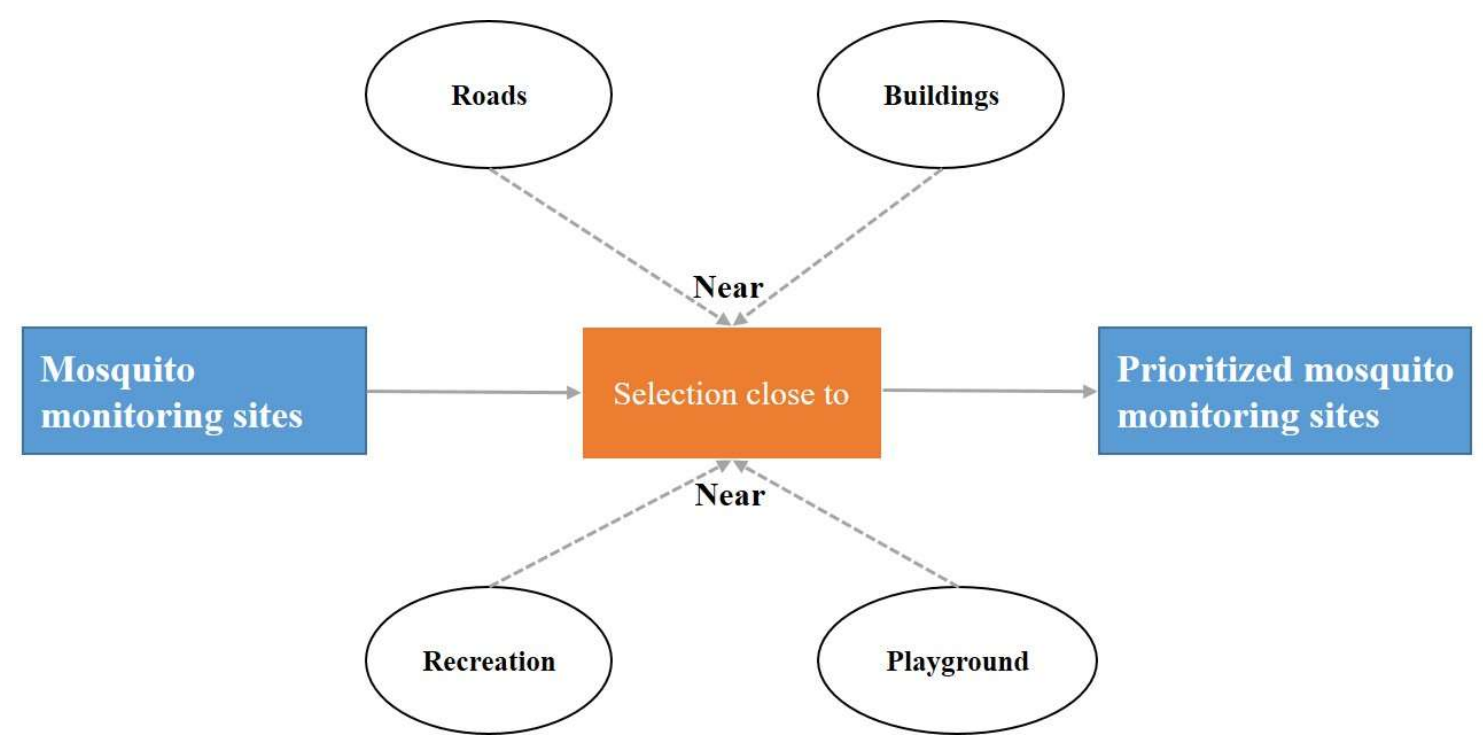

Figure 5-12: Proximity analysis of prioritized sites

Figure 5-12 explains the analysis process. The Near spatial operation was used to extract the potential sites that are within 400 feet from roads, buildings, playgrounds, and recreational areas. The tool interface is shown in Figure 5-13.

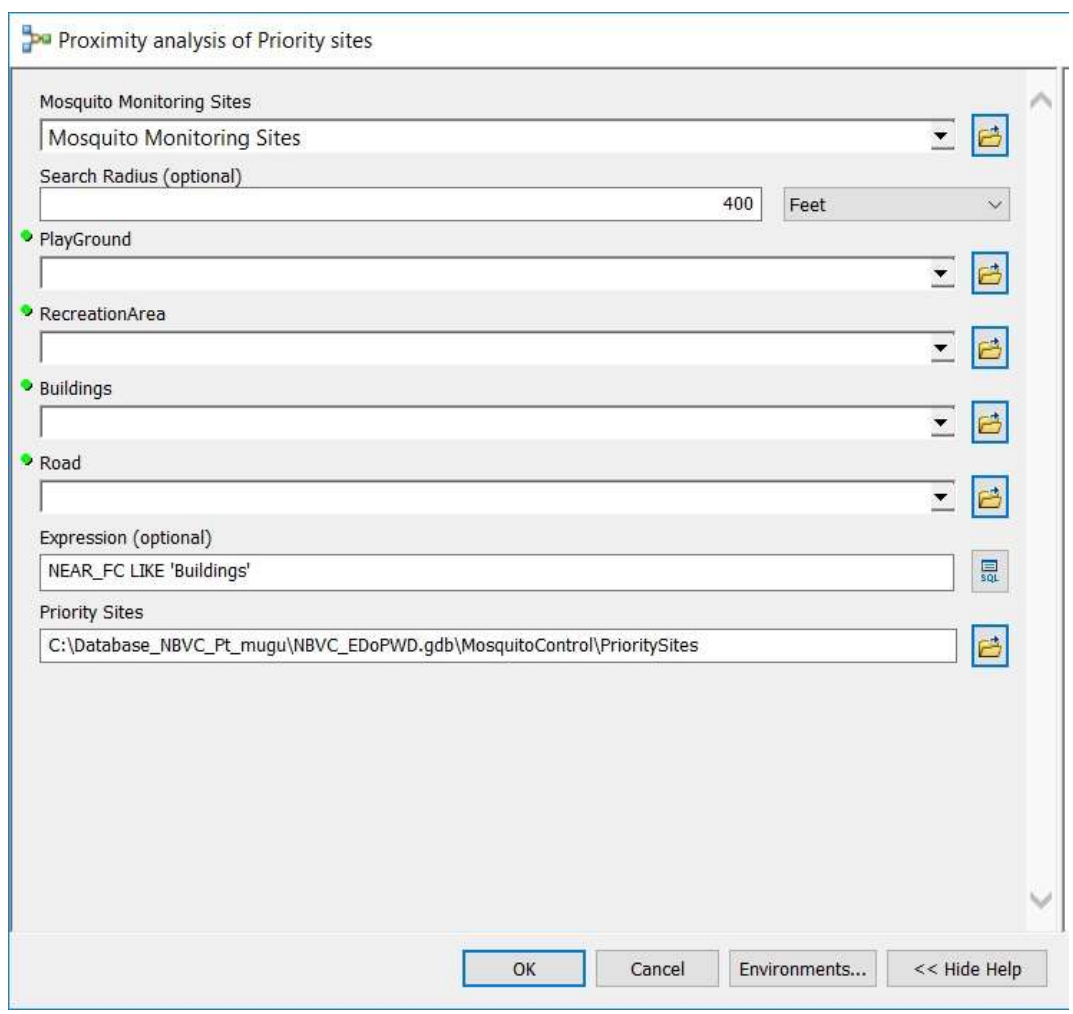

Figure 5-13: Proximity for prioritized sites model interface 
The user can change the distance parameter to their desired value to prioritize their survey and treatment.

\subsection{Summary}

The implementation of the three main elements of this project were outlined in this chapter: the predictive model for potential sites, the geodatabase for data and proximity analysis, and the visualization of mosquito control dataset. The technique used to predict potential sites was based on a modified bathtub approach and spatial analysis. 



\section{Chapter 6 - Results and Analysis}

The project results included a predictive potential site model of possible mosquito breeding areas, a geodatabase to record and track mosquito control data, and maps to guide field work. This chapter will focus on discussing project results as well as the challenges encountered. Sections 6.1 describes the existing monitoring sites. The predicted potential sites are discussed in sections 6.2 and 6.3. In particular, the intermediate results from the analyses are presented. Section 6.4 presents the proximity analysis result and the chapter ends with a summary.

\subsection{Existing Monitoring Sites}

The client has collected field data about where to treat the mosquitos. They hand drew these locations and named them as monitoring sites with various attributes including site ID, location, and notes. Figure 6-1 displays the existing monitoring sites.

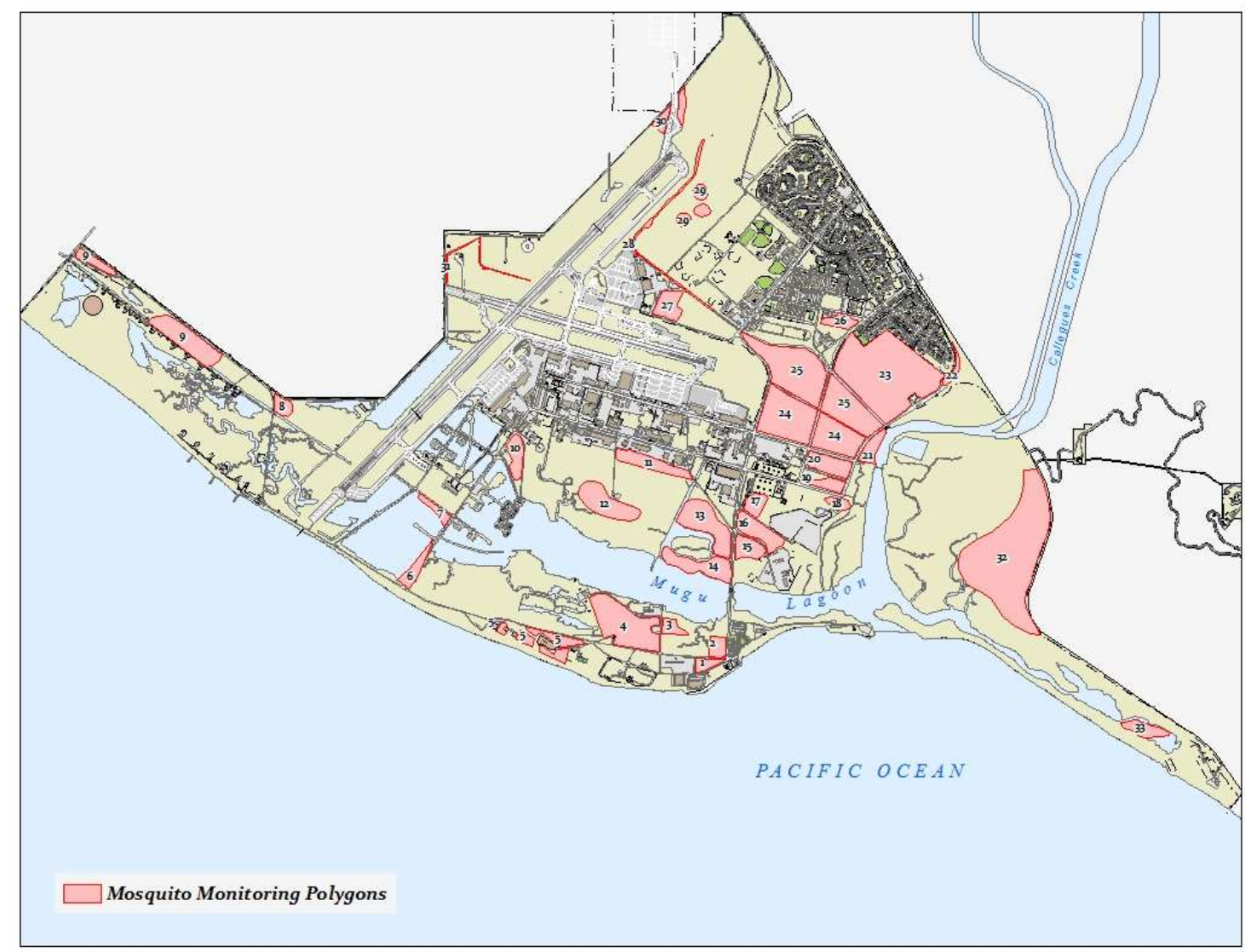

Figure 6-1: Existing Monitoring Sites

Given the limited resources, the client had difficulty to find new monitoring sites through field surveys. Therefore, predicting new sites was one of the objectives for this project. According to the literature, the potential breeding grounds are those high marsh 
zones. Therefore this study identified these areas with a predictive model as described in Chapter 5.

\subsection{Potential Breeding Sites}

Potential sites was the output of the predictive potential sites model. The potential sites generated from the model may vary depending on the variables used in the model. A change in the tidal surface variable or the elevation variable for drainage will affect the resulting output of potential breeding sites.

The predictive model involved various intermediate results to generate the potential sites. A closer look at these intermediate outputs will help understand the model. After the tidal surface was compared to the DEM, the areas below the water were identified. Figure 6-2 shows the extracted flooded areas. However, there are many tiny flooded areas that may be generated due to data errors.

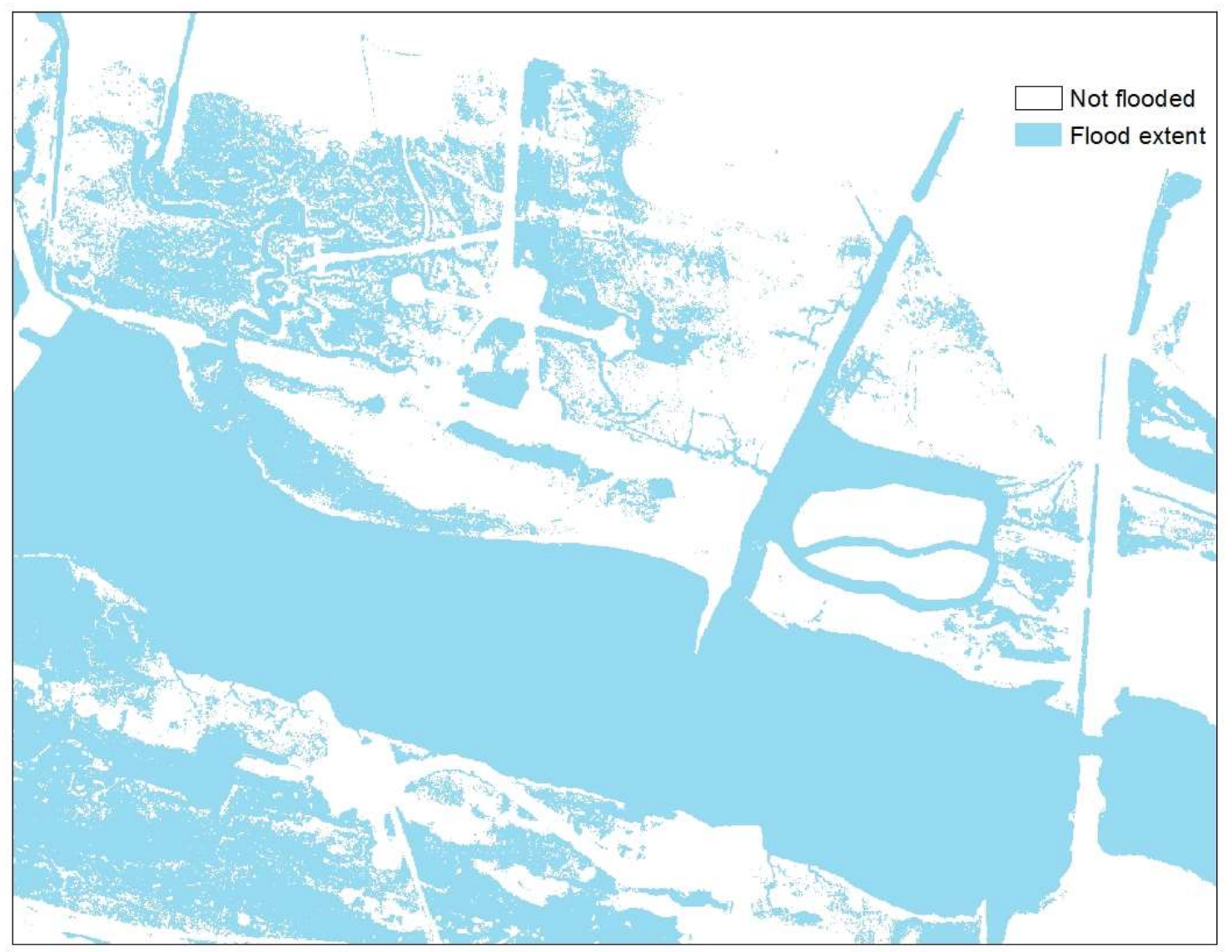

\section{Figure 6-2: Flood extent with noise}

To remove the noise in the raster of flooded areas, the morphological open operator was utilized. The process eliminated the noise contained in the raster of flooded areas as shown in Figure 6-3. The ginger pink areas are those that were removed from the original flooded areas. 


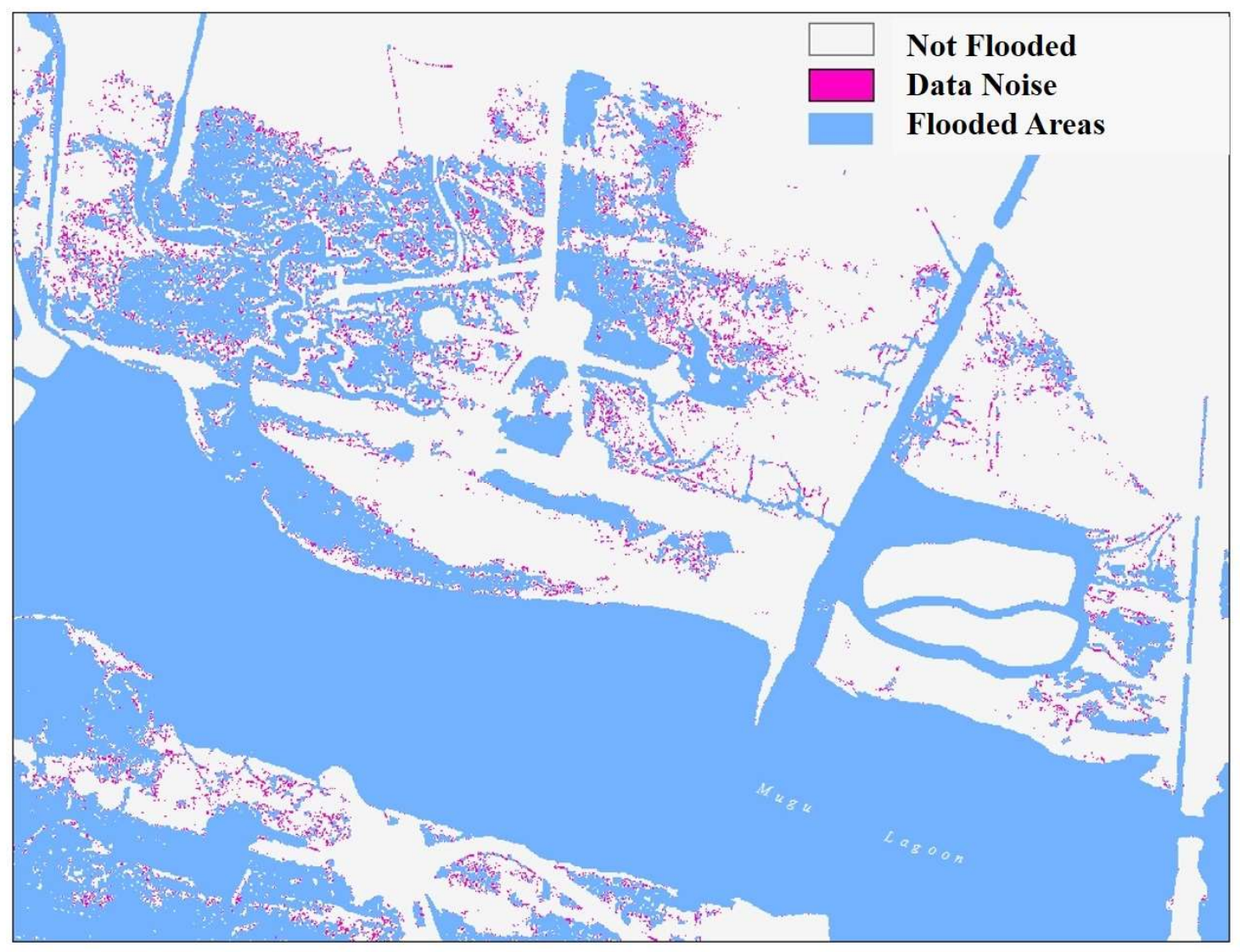

Figure 6-3: Flooded areas after noise was removed

Drainage was generated as an intermediate output of the predictive model. It was a representation of the lagoon channels, which includes the places with elevations lower than or equal to 4.7 feet. Figure 6-4 shows the drainage of the study area. 


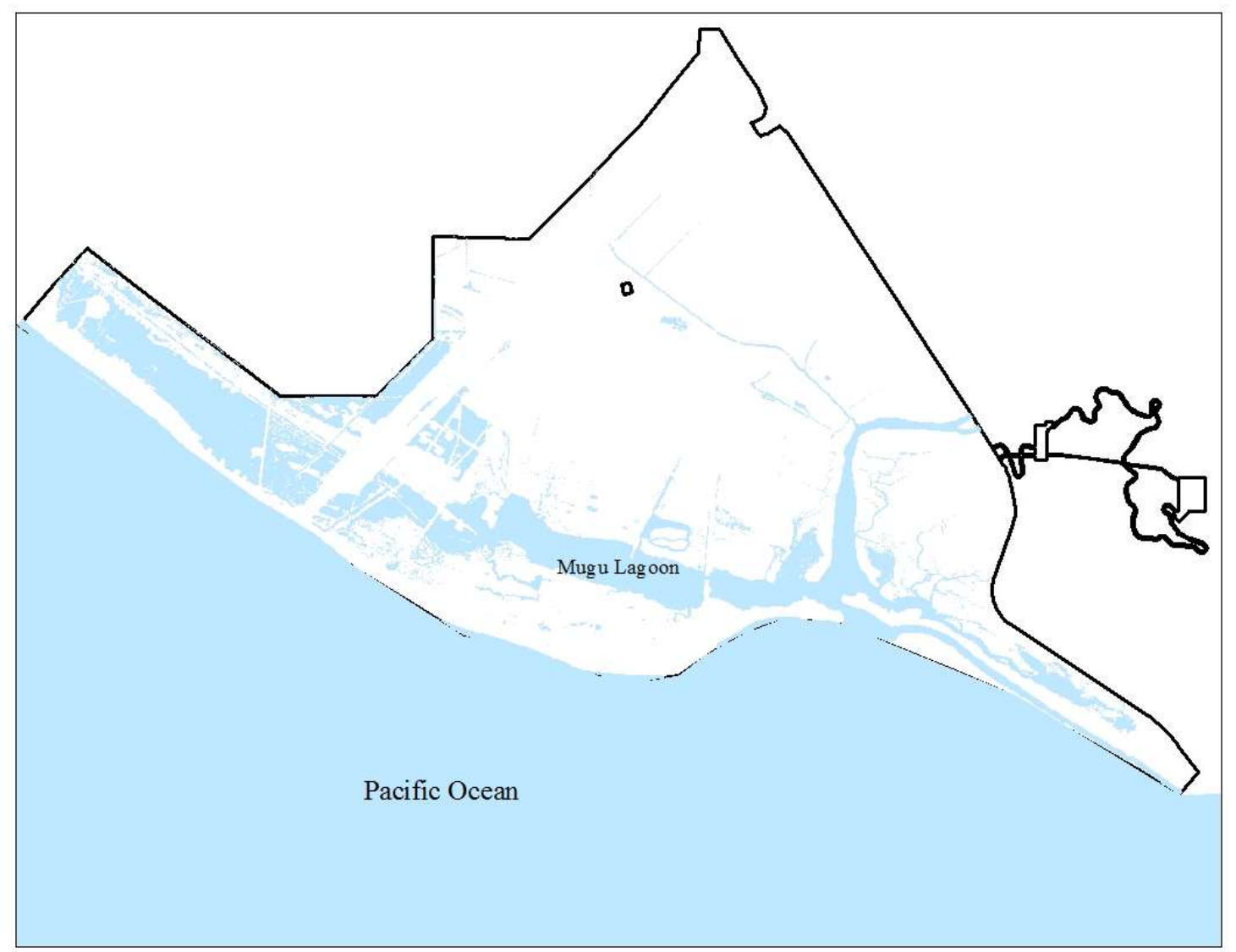

Figure 6-4: Point Mugu Lagoon drainage

The flooded areas that do not belong to the drainage network were extracted to form the final potential sites. These potential sites as shown in Figure 6-5 would be flooded after high tides of 5.2 feet and may hold stagnant water for black salt marsh mosquitos to breed. 


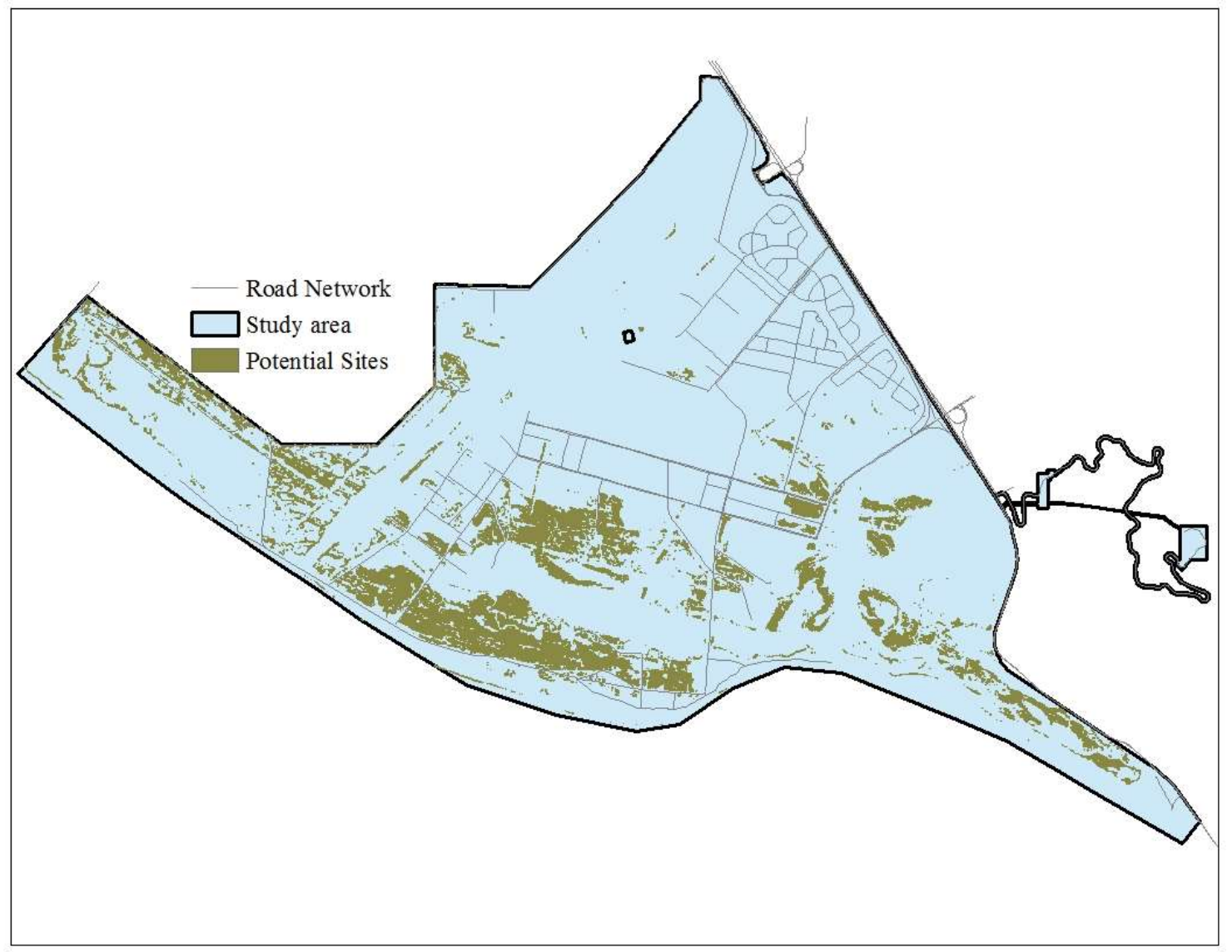

Figure 6-5: Potential salt marsh mosquito breeding sites (predictive model output)

It is worth pointing out that this model does not take into consideration other factors, such as weather and mosquito breeding seasons since the seasons are predefined from April to October (NBVC, 2012). The outcome of the analysis suggests the potential suitable breeding sites for salt marsh mosquitos for the dedicated seasons.

\subsection{Validating Predicted Breeding Sites}

The predictive model forecasts potential salt marsh mosquito breeding sites from the digital elevation model and the tidal surface. The result was compared to the field observations. An overview of the potential sites with the existing monitoring sites is displayed in Figure 6-6. 


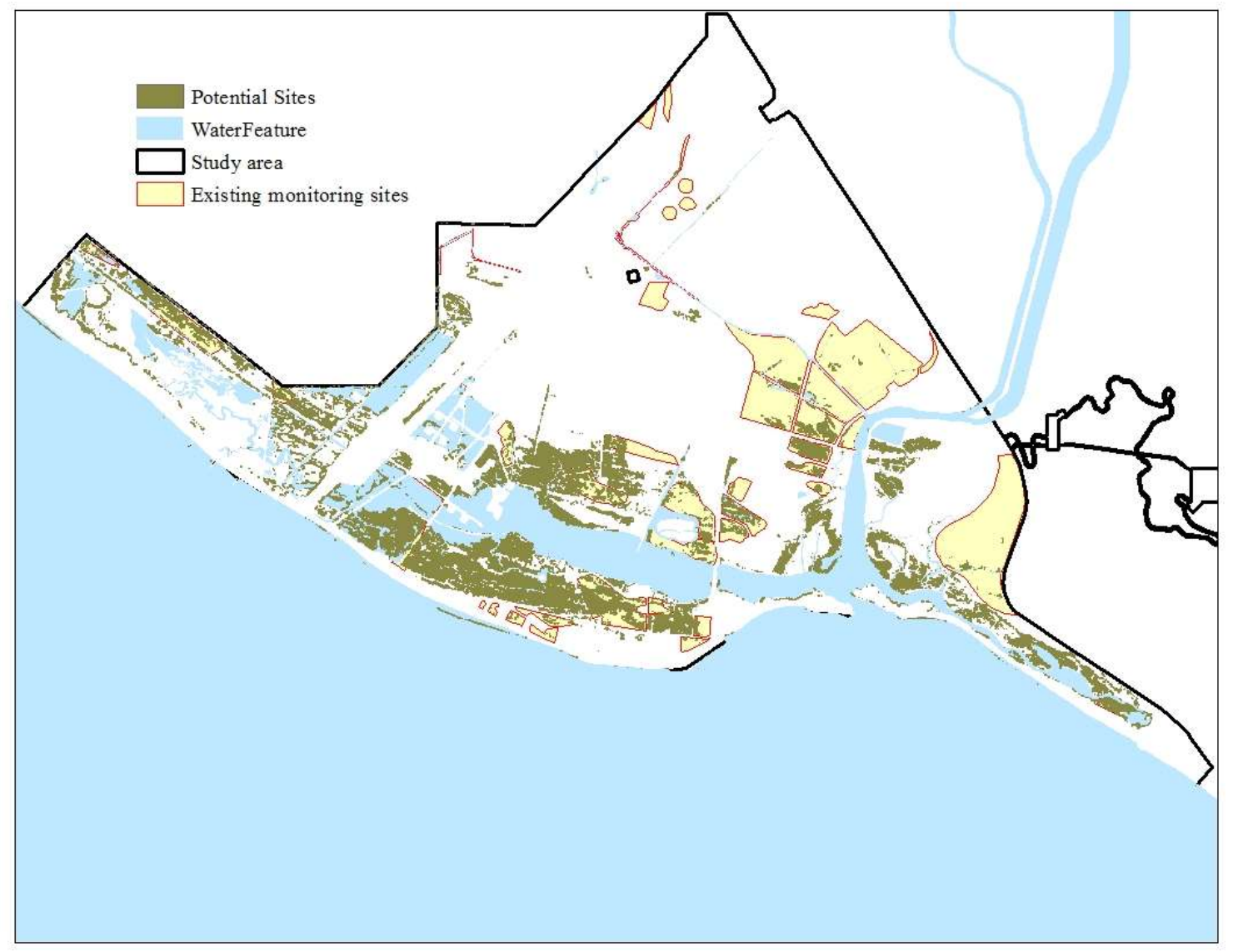

\section{Figure 6-6: Overview of potential sites and existing monitoring sites}

Of the 33 existing monitoring site, 4 of them do not overlap the predicted potential sites. Thus, approximately $88 \%$ of the existing mosquito monitoring sites overlapped with the predicted potential sites. It shows the majority of the existing monitoring sites are successfully predicted by the model, with only $12 \%$ of them missing from the predicted result. Since the existing monitoring sites were not complete, it was one of the objectives to add more potential monitoring sites. Therefore, another eighteen (18) polygons were digitized from the predicted sites that are not overlapped with the existing monitoring sites (Figure 6-7). The vegetative cover aided in the creation of these new monitoring sites. The new sites digitized were under the vegetation cover category of flooded fields. See appendix B for map of potential sites and vegetation cover. These polygons were digitized using the vegetation cover classes of flooded and tidal to target actual salt marsh mosquito breeding sites based on pre-existing data. The newly added ones were put into the monitoring polygon feature class as the subtype of "potential", while the original monitoring sites fall in the subtype of "monitoring". 


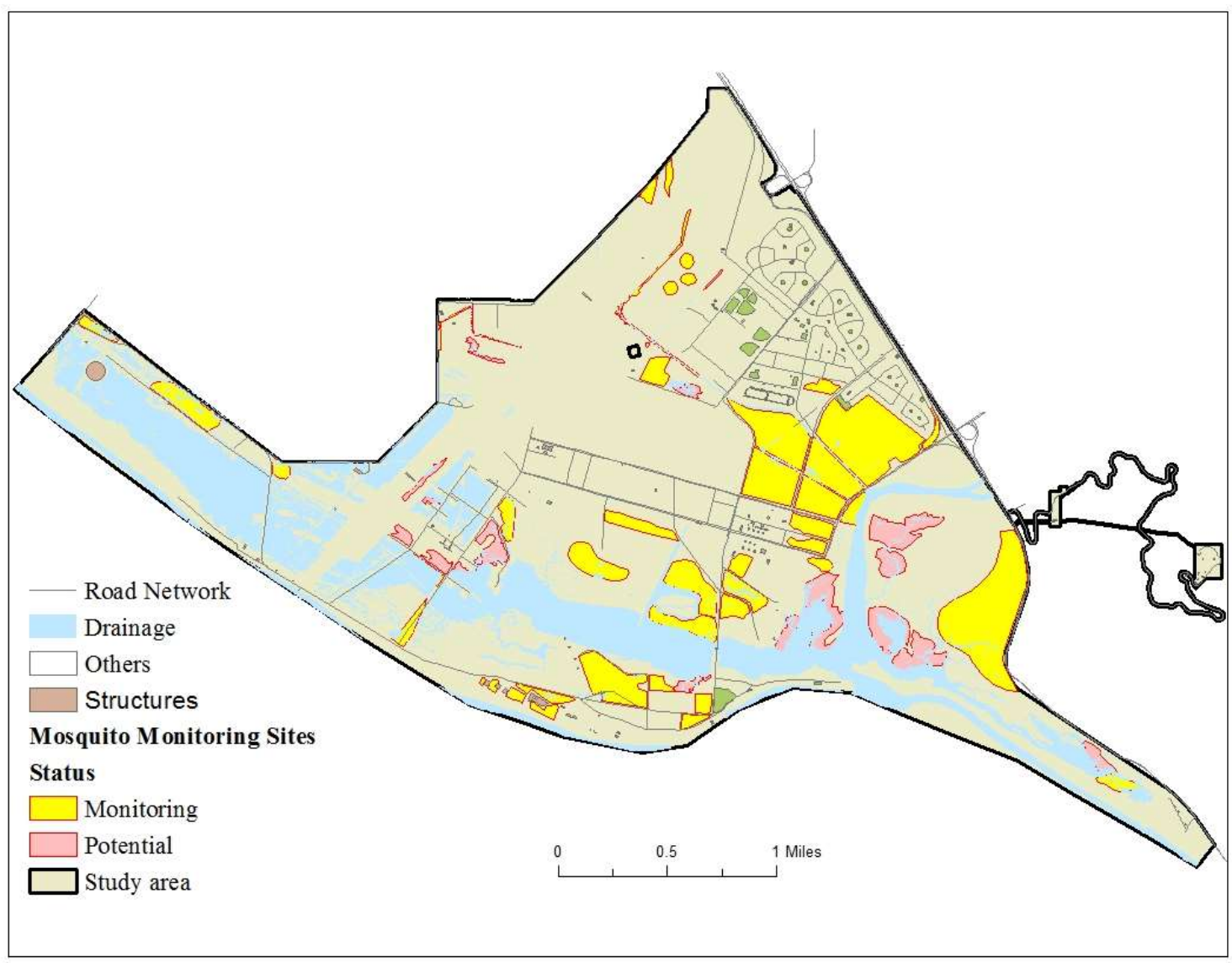

Figure 6-7: Mosquito monitoring sites showing existing sites "Monitoring" and new sites "Potential"

These digitized potential monitoring sites will help the client better plan field survey and treatment in the future. It will save both manpower needed to search for breeding ground and time that the staff may spend on creating maps and data entering.

\subsection{Proximity Analysis Result}

To further help the client prioritize client's field survey and treatment schedules, all monitoring sites including the newly added ones were examined based on their proximity to roads, playgrounds, recreational areas, and buildings. Figure 6-8 shows the prioritized monitoring sites that are located within 400 feet from the targeted features. 


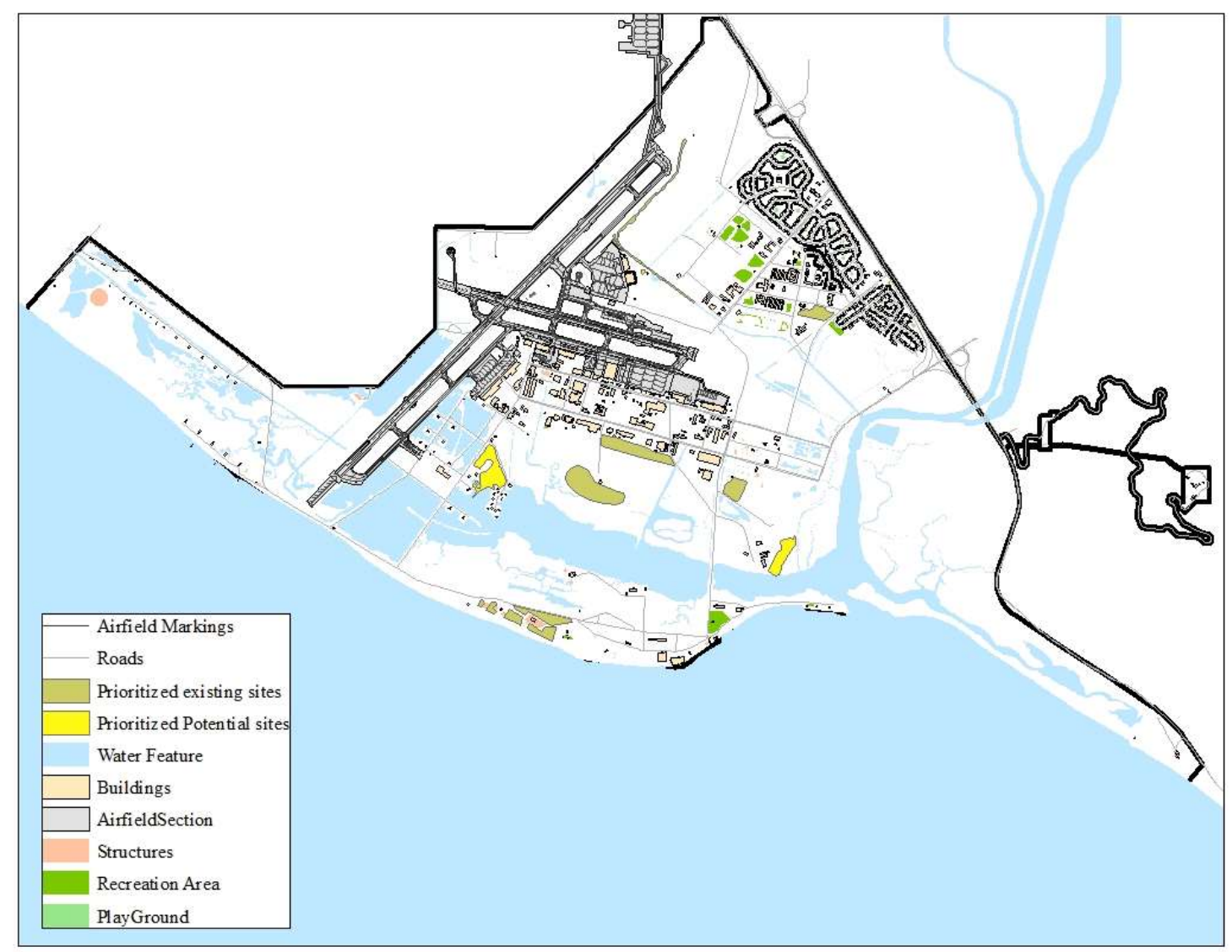

Figure 6-8: Prioritized sites from proximity analysis

Among these prioritized sites, 33 of them have been monitored, and 18 are the potential monitoring sites from the prediction. With this information, the client will be able to better plan treatment for each breeding season. They can also alter the proximity parameter of 400 feet to other values to get a different set of prioritized sites. For example, they can increase the distance parameter to include more areas if the resources permit.

The analysis results and the tools described in Chapter 5 are all included in the NBVC Point Mugu geodatabase. The client can update the database as needed. For example, they can digitize new potential monitoring sites, rerun the proximity analysis, or update the information about the monitoring sites. With the geodatabase, they can keep track of the mosquito control process, make maps to share with potential donors, and make informed decision.

\subsection{Summary}

This chapter presented the results and challenges of the geodatabase for salt marsh mosquito control. The process involved creating spatial relationships for mosquito control dataset and tools to predict and monitor potential breeding sites. The chapter also 
looked at the prediction of potential salt marsh mosquito breeding sites and the challenges encountered in the process. 



\section{Chapter 7 - Conclusions and Future Work}

This chapter concludes the project with a summary of the GIS approach to salt marsh mosquito control and the techniques for predicting potential mosquito breeding sites. The chapter also proposes recommendations for future work in salt marsh mosquito control.

\subsection{Summary}

Developing a GIS solution for salt marsh mosquito control had three objectives which provide decision-making support to help the NBVC Point Mugu adapt and adopt a new control management approach by prioritizing control effort to reducing mosquito populations. The objectives were met by creating a logical model, a file geodatabase for data recording and tracking mosquito control analysis, a predictive model for predicting salt marsh mosquito potential breeding sites, and creation of maps to aid field surveys and treatment.

The first primary objective was to develop a file geodatabase, which organizes salt marsh mosquito control datasets. The organized datasets in the geodatabase are the primary datasets needed to monitor, track, and manage salt marsh mosquito control efforts. Using the file geodatabase, the client is able to query desired information by location or by attribute to produce desired cartographic outputs. The geodatabase will increase efficiency in time management, tracking mosquito control activities, and resource allocation for effective mosquito control

The second objective was the predictive analysis to predict potential salt marsh mosquito breeding sites, which are areas that are inundated after high tides. A model was designed to come up with potential salt marsh mosquito breeding locations. The locations were then prioritized to identify potential salt marsh breeding locations.

The third objective was to create maps that show the classes treated sites, untreated sites, and monitoring sites. This serves as a guide for field work and using the dataset with constant updates, the NBVC Point Mugu will be able to track the effectiveness of control methods used.

Mosquito control, however, does not end at the stage of identifying and treating all known breeding sites. Neglected breeding sites might be prolific sources of breeding and the mosquitos may develop resistance over time to applicable treatments. Thus, mosquito control requires constant monitoring and updating of the dataset to effectively minimize the mosquito population.

\subsection{Future work}

This project provides the initial GIS framework for a geodatabase of salt marsh mosquito control and further spatial analysis on the prediction of potential breeding sites. The work so far is to initialize a GIS approach to salt marsh mosquito control and to predict potential sites. In order to accomplish a rigorous system of effective control, NBVC Point Mugu will need more field work data to categorized the areas upon prediction as well as keep track of records which can help them analyze the effectiveness of the control methods. 
The recommendations at this stage for future GIS work areas follows. First, to carry out control to verify the predicted potential salt marsh mosquito breeding sites are correct. Second, to record all field survey and treatment data regularly into the file geodatabase for possible analysis to track effectiveness of control methods. These data will be valuable in monitoring mosquito breeding sites and application of treatment based on the threshold recorded in each survey or treatment activities. Third, the NBVC Point Mugu can explore and integrate the fast evolving GIS techniques by using the ArcGIS Online capabilities to facilitate the work flow. This will cut time in field data collection and entering. The capabilities of ArcGIS online applications like Collector for ArcGIS and ArcGIS web app builder will be an enormous contribution in the salt marsh mosquito control. Finally is the creation of an automated geographic information system of prediction with a constant feedback on online mapping application for salt marsh mosquito control.

To conclude, NBVC Point Mugu now has an organized spatial database for mosquito control data. This organized spatial database will cut time and cost in mosquito control through identification of potential sites and mapping of location based on treated or untreated. The solution will be implemented by the Naval Base in the 2017 mosquito breeding season. 


\section{Works Cited}

Bash, E. (2015). The Incorporation of GIS into a Local Mosquito control program. PhD Proposal, (June). http://doi.org/10.1017/CBO9781107415324.004

CDC. (2016). Preliminary Maps \& Data for 2015 | West Nile Virus | CDC. Retrieved March 12, 2016, from http://www.cdc.gov/westnile/statsmaps/preliminarymapsdata/index.html

EPA. (2012). Joint Statement on Mosquito Control in the United States. Retrieved from https://www.epa.gov/mosquitocontrol/joint-statement-mosquito-control-unitedstates

FEMA. (n.d.). Guidelines and Standards for Flood Risk Analysis and Mapping. Retrieved January 1, 2016, from http://www.fema.gov/guidelines-and-standards-flood-riskanalysis-and-mapping

Fillinger, U., \& Lindsay, S. W. (2011). Larval source management for malaria control in Africa: myths and reality. Malaria Journal, 10, 353. http://doi.org/10.1186/14752875-10-353

Freeborn, S. B. (2013). The mosquitoes of California. University of Massachussets Amherst.

Granados-Echegoyen, C., Pérez-Pacheco, R., Soto-Hernández, M., Ruiz-Vega, J., Lagunez-Rivera, L., Alonso-Hernandez, N., \& Gato-Armas, R. (2014). Inhibition of the growth and development of mosquito larvae of Culex quinquefasciatus (Diptera: Culicidae) treated with extract from leaves of Pseudocalymma alliaceum (Bignonaceae). Asian Pacific Journal of Tropical Medicine, 7(8), 594-601. http://doi.org/10.1016/S1995-7645(14)60101-2

Hayes, R., Maxwell, E. L., Mitchell, C. J., \& Woodzick, T. L. (1985). Detection identification and classification of mosquito larval habitats using remote sensing scanners in earth-orbiting satellites, 63(April 1975), 361-374.

Killeen, G. F., Fillinger, U., Kiche, I., Gouagna, L. C., \& Knols, B. G. (2002). Eradication of Anopheles gambiae from Brazil: lessons for malaria control in Africa? The Lancet Infectious Diseases, 2(10), 618-627. http://doi.org/10.1016/S1473-3099(02)00397-3

Kronenwetter-Koepel, T. A., Meece, J. K., Miller, C. A., \& Reed, K. D. (2005). Surveillance of above- and below-ground mosquito breeding habitats in a rural midwestern community: baseline data for larvicidal control measures against West Nile Virus vectors. Clinical Medicine \& Research, 3(1), 3-12.

Li, L., Bian, L., Yakob, L., Zhou, G., \& Yan, G. (2009). Temporal and spatial stability of Anopheles gambiae larval habitat distribution in Western Kenya highlands, 11, 111. http://doi.org/10.1186/1476-072X-8-70

NBVC. (2012a). FY2010 Secretary of Defense Environmental Award Large Installation Natural Resources Conservation. Retrieved from http://greenfleet.dodlive.mil/files/2012/09/NRC-LI_NBVC_FY10.pdf

NBVC. (2012b). Notice of Intent (NOI) Naval Base Ventural County. Retrieved February 27, 2016, from http://www.waterboards.ca.gov/water_issues/programs/npdes/docs/aquatic/noi_pap/ navalbase_ventura.pdf 
NOAA. (1990). Superseded Bench Mark Sheet for 9411340, Santa Barbara CA. Retrieved from https://tidesandcurrents.noaa.gov/benchmarks.html?id=9411340\&type=superseded

NOAA. (2012). Detailed Methodology for Mapping Sea Level Rise Inundation, (May), 5. Retrieved from http://www.csc.noaa.gov/slr/viewer/assets/pdfs/Inundation_Methods.pdf

Poppenga, S., \& Worstell, B. (2015). Evaluation of airborne lidar elevation surfaces for propagation of coastal inundation: The importance of hydrologic connectivity. Remote Sensing, 7(9), 11695-11711. http://doi.org/10.3390/rs70911695

Poulter, B., \& Halpin, P. N. (2008). Raster modelling of coastal flooding from sea-level rise. International Journal of Geographical Information Science, 22(2), 167-182. http://doi.org/10.1080/13658810701371858

Rejmánková, E., Grieco, J., Achee, N., \& Roberts, D. R. (2013). Ecology of Larval Habitats. Anopheles Mosquitoes - New Insights into Malaria Vectors, 1(2), 813. http://doi.org/10.5772/55229

Rochlin, I., Iwanejko, T., Dempsey, M. E., \& Ninivaggi, D. V. (2009). Geostatistical evaluation of integrated marsh management impact on mosquito vectors using before-after-control-impact (BACI) design. International Journal of Health Geographics, 8, 35. http://doi.org/10.1186/1476-072X-8-35

Rozsa, R. (1995). Human Impacts on Tidal Wetlands : History and Regulations. Connecticut Department of Environmental Protection.

Yunus, A., Avtar, R., Kraines, S., Yamamuro, M., Lindberg, F., \& Grimmond, C. (2016). Uncertainties in Tidally Adjusted Estimates of Sea Level Rise Flooding (Bathtub Model) for the Greater London. Remote Sensing, 8(5), 366. http://doi.org/10.3390/rs8050366

Zou, L., Miller, S. N., \& Schmidtmann, E. T. (2006). Mosquito larval habitat mapping using remote sensing and GIS: implications of coalbed methane development and West Nile virus. J Med Entomol, 43(5), 1034-1041. Retrieved from http://www.ncbi.nlm.nih.gov/pubmed/17017244 


\section{Appendix A. Predicting Potential Site Model Diagram}






\section{Appendix B. Overview of Vegetation cover and Potential Sites}

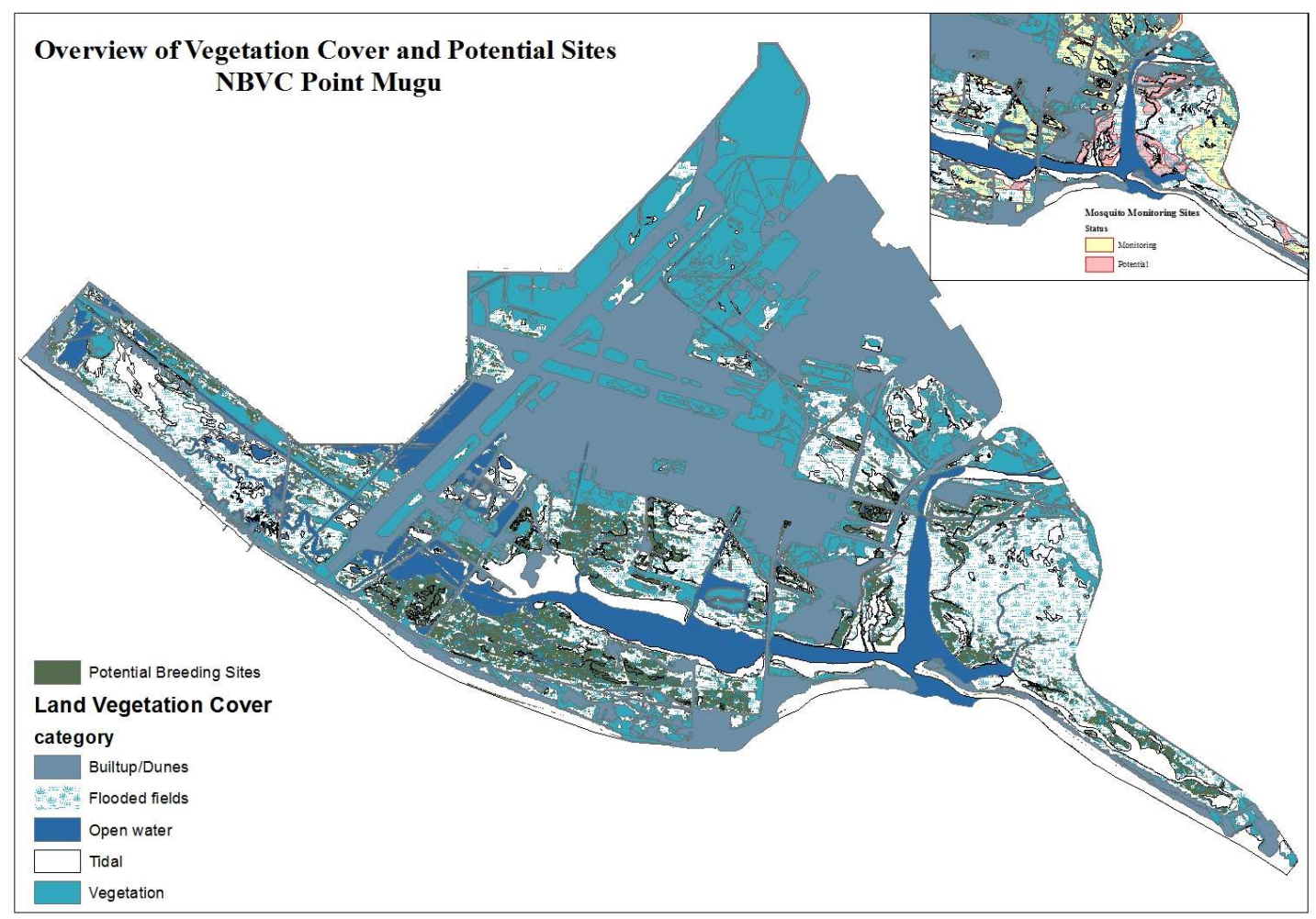

